University of Wollongong

Research Online

Faculty of Engineering and Information

Faculty of Engineering and Information

Sciences - Papers: Part A

Sciences

$1-1-2020$

Ecological, economical and technological perspectives based sustainability assessment in hybrid-cooling assisted machining of Ti-6Al-4 $\mathrm{V}$ alloy

Munish Gupta

Qinghua Song

Zhanqiang Liu

Murat Sarikaya

Muhammad Jamil

See next page for additional authors

Follow this and additional works at: https://ro.uow.edu.au/eispapers

Part of the Engineering Commons, and the Science and Technology Studies Commons

Research Online is the open access institutional repository for the University of Wollongong. For further information contact the UOW Library: research-pubs@uow.edu.au 


\title{
Ecological, economical and technological perspectives based sustainability assessment in hybrid-cooling assisted machining of Ti-6Al-4 $\mathrm{V}$ alloy
}

\author{
Abstract \\ (C) 2020 Elsevier B.V. Ti-6Al-4 V alloy is a well-acknowledged standard material for the application of \\ modern aerospace, surgical equipment, and prosthetic body parts owing to its stable thermo-physical \\ properties at elevated temperature. However, this structure stability imparts its low thermal conductivity \\ that leads to buildup of heat at tool-workpiece interface during machining which subsequently has a \\ damaging effect on the tool cutting edge. Several biodegradable cutting fluids have already been \\ attempted controlling the heat generation, environmental footprints to improve the overall machinability. \\ In this endeavor, the effectiveness of dry, liquid nitrogen (LN2) and hybrid cryogenic and minimum \\ quantity lubrication (LN2 + MQL) conditions was evaluated in terms of important machinability indicators \\ for instance surface roughness, cutting forces and temperature. The environmental parameters such as \\ total cycle time, productivity, economic analysis, energy consumption and carbon emissions were also \\ analyzed under these cooling conditions. Lastly, the sustainability assessment of process parameters \\ was calculated with the help of the Analytic Hierarchy Process (AHP) coupled with the Technique for \\ Order Preference Based on Similarity to Ideal Solution (TOPSIS) techniques. Findings have exhibited \\ superior cooling/lubrication effect under LN2 + MQL conditions lowering the machining as well as \\ environmental indices. The improvement in cycle time and productivity of LN2 and LN2 + MQL was \\ appeared to be $29.01 \%$ and $34.21 \%$ as compared with dry turning. The sustainability assessment results \\ also revealed that the lower cutting parameters under LN2 + MQL produced best results to achieve the \\ overall sustainability index.

\section{Disciplines} \\ Engineering | Science and Technology Studies

\section{Publication Details} \\ Gupta, M., Song, Q., Liu, Z., Sarikaya, M., Jamil, M., Mia, M., Kushvaha, V., Singla, A. \& Li, Z. (2020). \\ Ecological, economical and technological perspectives based sustainability assessment in hybrid-cooling \\ assisted machining of Ti-6Al-4 V alloy. Sustainable Materials and Technologies, 26
}

\section{Authors}

Munish Gupta, Qinghua Song, Zhanqiang Liu, Murat Sarikaya, Muhammad Jamil, Mozammel Mia, Vinod Kushvaha, Anil Singla, and Zhixiong Li 


\title{
Ecological, economical and technological perspectives based sustainability assessment in hybrid-cooling assisted machining of Ti-6Al-4 V alloy
}

\author{
Munish Kumar Gupta ${ }^{\mathrm{a}}$, Qinghua Song a,b,* Zhanqiang Liu ${ }^{\mathrm{a}, \mathrm{b}}$, Murat Sarikaya ${ }^{\mathrm{c}}$, Muhammad Jamil ${ }^{\mathrm{d}}$, \\ Mozammel Mia ${ }^{\mathrm{e}}$, Vinod Kushvaha ${ }^{\mathrm{f}}$, Anil Kumar Singla ${ }^{\mathrm{g}}$, Zhixiong $\mathrm{Li}^{\mathrm{h}}$ \\ a Key Laboratory of High Efficiency and Clean Mechanical Manufacture, Ministry of Education, School of Mechanical Engineering, Shandong University, PR China \\ ${ }^{\mathrm{b}}$ National Demonstration Center for Experimental Mechanical Engineering Education, Shandong University, Jinan, PR China \\ c Department of Mechanical Engineering, Sinop University, Sinop, Turkey \\ d College of Mechanical and Electrical Engineering, Nanjing University of Aeronautics and Astronautics, Nanjing 210016, PR China \\ e Department of Mechanical Engineering, Imperial College London, South Kensington, SW7 2AZ London, United Kingdom \\ ${ }^{\mathrm{f}}$ Department of Civil Engineering, Indian Institute of Technology Jammu, Jammu, JEK, India \\ ${ }^{g}$ Department of Mechanical Engineering, SLIET, Longowal 148106, Punjab, India \\ h School of Mechanical, Materials, Mechatronic and Biomedical Engineering, University of Wollongong, NSW 2522, Australia
}

\section{A R T I C L E I N F O}

\section{Article history:}

Received 6 August 2020

Received in revised form 22 August 2020

Accepted 27 August 2020

Available online $\mathrm{xxxx}$

\section{Keywords:}

Carbon emissions

Energy consumption

Economical

Titanium alloy

Sustainability assessment

\begin{abstract}
A B S T R A C T
Ti-6Al-4 V alloy is a well-acknowledged standard material for the application of modern aerospace, surgical equipment, and prosthetic body parts owing to its stable thermo-physical properties at elevated temperature. However, this structure stability imparts its low thermal conductivity that leads to buildup of heat at toolworkpiece interface during machining which subsequently has a damaging effect on the tool cutting edge. Several biodegradable cutting fluids have already been attempted controlling the heat generation, environmental footprints to improve the overall machinability. In this endeavor, the effectiveness of dry, liquid nitrogen ( $\left.\mathrm{LN}_{2}\right)$ and hybrid cryogenic and minimum quantity lubrication ( $\left.\mathrm{LN}_{2}+\mathrm{MQL}\right)$ conditions was evaluated in terms of important machinability indicators for instance surface roughness, cutting forces and temperature. The environmental parameters such as total cycle time, productivity, economic analysis, energy consumption and carbon emissions were also analyzed under these cooling conditions. Lastly, the sustainability assessment of process parameters was calculated with the help of the Analytic Hierarchy Process (AHP) coupled with the Technique for Order Preference Based on Similarity to Ideal Solution (TOPSIS) techniques. Findings have exhibited superior cooling/lubrication effect under $\mathrm{LN}_{2}+\mathrm{MQL}$ conditions lowering the machining as well as environmental indices. The improvement in cycle time and productivity of $\mathrm{LN}_{2}$ and $\mathrm{LN}_{2}+\mathrm{MQL}$ was appeared to be $29.01 \%$ and $34.21 \%$ as compared with dry turning. The sustainability assessment results also revealed that the lower cutting parameters under $\mathrm{LN}_{2}+\mathrm{MQL}$ produced best results to achieve the overall sustainability index.
\end{abstract}

(C) 2020 Elsevier B.V. All rights reserved.

\section{Introduction}

Sustainable manufacturing is the creation of components/products through an energy-efficient, cheaper, and non-polluting process in order to ensure social well-being, safety, and health [1]. The sustainability of the machining process is highly dependent upon machining parameters, workpiece materials and cooling/lubrication systems [2]. Possession of many desirable characteristics for instances excellent

Abbreviations: AHP, Analytic Hierarchy Process; EPA, Environmental Protection Association; $\mathrm{LN}_{2}$, Liquid nitrogen; MQL, Minimum quantity lubrication; CO ${ }_{2}$, Carbon dioxide; LCA, Life

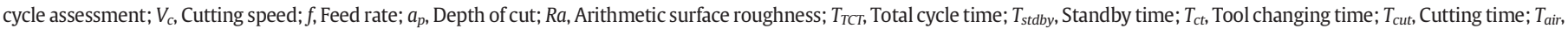

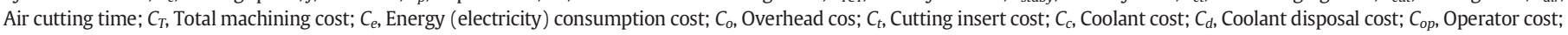

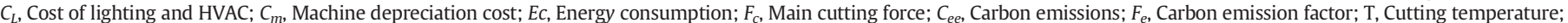
$\mathrm{LN}_{2}+\mathrm{MQL}$, Hybrid cryogenic and minimum quantity lubrication; TOPSIS, Technique for Order Preference Based on Similarity to Ideal Solution.

* Corresponding author at: Key Laboratory of High Efficiency and Clean Mechanical Manufacture, Ministry of Education, School of Mechanical Engineering, Shandong University, PR China.

E-mail addresses: munishguptanit@gmail.com (M.K. Gupta), ssinghua@sdu.edu.cn (Q. Song), melius@sdu.edu.cn (Z. Liu), msarikaya@sinop.edu.tr (M. Sarikaya),

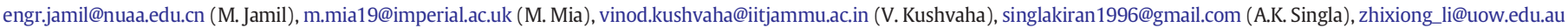
(Z. Li). 
corrosion endurance, strength to weight ratio and elevated fatigue performance by titanium alloys has made it the best candidate for widespread use, especially as biomaterials and aerospace sector. Ti-6Al-4 V being most important alloy of titanium industry has high thermal softening resistance, stable $\alpha+\beta$ structure and constitute $50 \%$ of the usage of titanium and its alloys [3,4]. Although, Ti-6Al-4 $\mathrm{V}$ has superior thermo-physical characteristics, however, poor thermal conductivity, chip-contact angle, and high chemical reactivity towards tool materials, damage the tool material and cause large edge wear [5].

Conventional emulsions, having cooling/lubrication characteristics, play an essential role in limiting the tool wear, improving product quality, and overall machinability. However, the massive use of emulsions is dangerous for ecology, air, soil and water resources. The global consumption of conventional emulsions in 2016 was about 13,726 million Tons with a $1 \%$ annual increment. The reduction of natural energy resources and $13-50 \%$ loss of natural lubricants is an alarming situation for ecological complexities. Therefore, the exploration of green cutting is inevitable to open new avenues for the adoption of biodegradable oil as an alternative to mineral-based emulsions [6,7]. Recently, new cooling/lubrication techniques have been coined with the emerging trends of sustainable manufacturing and strict regulations by EPA (Environmental Protection Association). Considering the sustainability and cleaner production, dry-cutting, MQL, cryogenic cooling and hybrid cooling techniques are applied with advantages of near dry surface, zero post-operation cleaning (refer Fig. 1) [8].

Lei and Liu (2002) performed machining tests on titanium alloy under dry conditions and observed the behavior of the material [9]. The author's findings have depicted smearing, chip welding on tool rake face, and newly generated surface. At raised temperature resulting from high cutting speed, Ti-6Al-4 V showed chemical affinity, and the alloying tendency towards tool-material leading to high tool wear. On the contrary, MQL improved the machined surface quality, dissipated heat through convection and evaporation [10,11]. The fact that MQL reduces the Tons of cutting fluids to milliliters $(10-100 \mathrm{ml} / \mathrm{h}$ ) by providing fine mist of air-oil sprinkled on the workpiece surface is noteworthy. The lower temperature during cutting is also critical to arrest the tendency of chemical affinity of Ti-6Al-4 V towards tool material. Therefore, it has been claimed that the application of cryogenic cooling is popular during machining difficult to cut materials. The cryogenic- $\mathrm{LN}_{2}$ absorbs heat, evaporates quickly (lighter than air), forming a protection layer

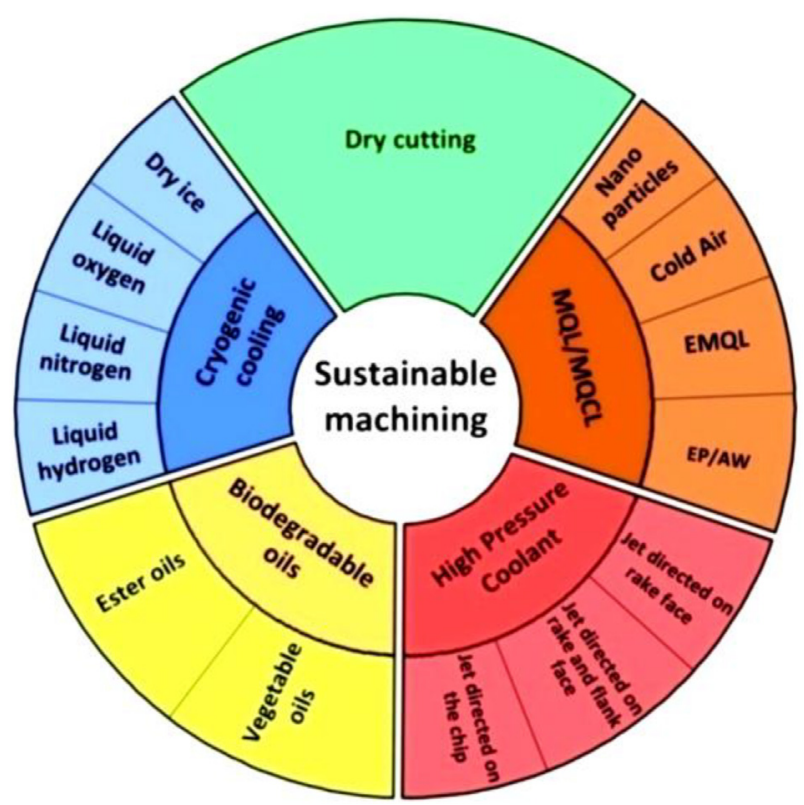

Fig. 1. Ring of sustainable machining [8]. on the workpiece surface and limiting the cutting temperature. The chip remains dry, reduces chip adhesion and diffusion, results in minor damage of tool and causes lesser edge wear. Although biodegradable oil-based MQL diminishes the Tons of cutting fluids and cooling cost; however, it's not enough to provide superior thermal conductivity, dissipating heat efficiently, and adequate lubrication [12]. Therefore, the hybridization of cryogenic cooling with MQL is effective and clean option to achieve high efficient heat dissipation capability of MQL mist [13].

\subsection{Eco-benign cooling strategies}

Environmental innocuous cooling is already under research with the self-pressured $\mathrm{LN}_{2}$ cooling and MQL [14]. In both systems, the pressured coolant along with the supply of air is applied through the nozzle on the tool rake/flank face. Reduction in temperature under cryogenic and MQL is essential in both rough and finish turning of difficult-to-cut materials. Efficient cooling is highly associated with heat removal from the contact interface and they got the full attention of researchers owing to the provision of sustainable and efficient titanium machining characteristics. In turning of titanium and its alloys, the performance of six cooling conditions i.e., dry, $\mathrm{LN}_{2}$, carbon dioxide $\left(\mathrm{CO}_{2}\right), \mathrm{MQL}, \mathrm{CO}_{2}+\mathrm{MQL}$ and $\mathrm{LN}_{2}+\mathrm{MQL}$ was compared by Iqbal et al., (2019) [15]. The key factors investigated in this study were cutting forces, tool wear, surface roughness and total energy consumption. The outcomes divulged that the hybrid cooling conditions along with the MQL conditions provided the lower results of responses. M. et al., (2020) have compared the performance of $\mathrm{LN}_{2}$ and $\mathrm{CO}_{2}$-Snow with conventional emulsion in milling of $55 \mathrm{NiCrMoV7}$ steel [16]. The performance of these coolants was compared with regard to temperature, feed, thrust force, surface roughness, and tool wear. Outcomes have depicted that $\mathrm{CO}_{2}$-snow and $\mathrm{LN}_{2}$ reduced $50.49 \%$ and $53.97 \%$ temperature contrasted to emulsion cooling. It is pertinent to state that lower surface roughness of $0.17-0.22 \mu \mathrm{m}$ has been detected under $\mathrm{CO}_{2}$-snow and $0.22-0.39 \mu \mathrm{m}$ under $\mathrm{LN}_{2}$ cooling. In addition, surface topography and chip morphology were improved under the $\mathrm{CO}_{2}$-snow environment. Also, the application of $\mathrm{LN}_{2}$ at high temperatures reduced the cooling efficiency due to the insulating layer that reduces the cooling efficiency and dimensional inaccuracies. However, $\mathrm{LN}_{2}$ is also non-toxic, benign, and ensure the feasibility of attaining high MRR. Shokrani et al., (2019) compared the results of wet, MQL, $\mathrm{LN}_{2}$ and hybrid $\mathrm{LN}_{2}+\mathrm{MQL}$ conditions during end milling of titanium alloys [17]. The tool life, surface roughness and tool wear has been considered as key machining evaluators during machining under different cooling conditions. The hybrid cooling technique proposed that the tool life has been improved by 30 times and surface roughness is reduced by $50 \%$ with the hybrid cooling conditions. Sartori et al., (2017) explored the effect of different cooling conditions i.e., dry, wet, $\mathrm{MQL}, \mathrm{LN}_{2}, \mathrm{CO}_{2}, \mathrm{CO}_{2}+\mathrm{MQL}$ and $\mathrm{LN}_{2}+\mathrm{MQL}$ on the wear behavior of WC inserts and surface integrity aspects during machining Ti-6Al-4 V alloy [18]. Findings have depicted extended tool life and surface finishing under hybrid cooling conditions under high flow rates. Schoop et al., (2017) applied $\mathrm{LN}_{2}, \mathrm{LN}_{2}+\mathrm{MQL}$ and wet cooling in metal cutting of Ti-6Al-4 V [19]. Outcomes have depicted extended tool life of the cutting tool by about 30\% and 60\% during turning of Inconel-718 and Ti6Al-4 V respectively. Dilip Jerold and Pradeep Kumar (2012) performed turning of AISI-1045 steel compared wet cooling, $\mathrm{LN}_{2}$, and CO2-snow cooling in connection with temperature, cutting forces, surface roughness, and chip morphology [20]. The authors have observed that $\mathrm{LN}_{2}$ has $9-34 \%$ and $3-17 \%$ less temperature than emulsion and $\mathrm{CO}_{2}$-snow cooling. CO2-snow lowered the cutting forces about $17-38 \%$ and $2-12 \%$ compared to the emulsion and $\mathrm{LN}_{2}$ cooling.

From the open literature, it is interesting to claim that the dry machining, cryogenic machining and hybrid cryogenic and MQL machining conditions are considered in the category of eco-benign cooling conditions. These cooling conditions boost the productivity, product quality, superior surface finish, and heat dissipation capacity under the metal 
cutting of hard-to-cut materials. However, the environmental impacts of these cooling conditions are still missing in the literature. Some former researchers have implemented the various sustainability assessment methods like life cycle assessment (LCA) and other empirical methods in literature. For instance, Gupta et al., (2020) implemented the LCA method in machining of difficult to machine material [21]. The environmental impacts between two cooling conditions were calculated with the help of Simapro software. In another work, Hegab et al., (2018) used the empirical sustainability assessment model to evaluate the effect of metal cutting conditions on environmental aspects [22]. The same model was also implemented in the work of Khan et al., (2020) and the environmental assessment was done on selected cooling conditions [23]. In literate, some artificial intelligence methods were also implemented to improve the process performance [24-26]. Therefore, this paper follows the same trend and the machining investigations along with the sustainability assessment have been performed under dry, $\mathrm{LN}_{2}$ cooling and hybrid $\mathrm{LN}_{2}+\mathrm{MQL}$ cooling conditions. The AHP method coupled with TOPSIS techniques has been adopted to calculate the overall sustainability index under specified cooling conditions. Initially, the productivity, cycle time, machining cost, energy consumption, carbon emissions, surface roughness, cutting temperature and cutting forces were measured and calculated. Then, the parametric impact has been analyzed and the results were compared with each other. The complete details are presented in the following subsections.

\section{Experimental setup}

This section provides the details about the selection of machining parameters, experimental setup, cooling modes, tool geometry parameters and response measurements.

\subsection{Workpiece material, process parameters and experimental design}

In present work, the turning experiments were performed on commercially available titanium alloy Ti-6Al-4 V. The subjected alloy was heat treated (Hardness 35 HRC) and machined under three different sustainable/green cooling conditions i.e., dry, $\mathrm{LN}_{2}$ and hybrid $\mathrm{LN}_{2}+\mathrm{MQL}$ conditions, respectively. Cutting speed $\left(V_{c}\right)$ of $100,125,150 \mathrm{~m} / \mathrm{min}$ and feed rate $(f)$ of $0.10,0.125$ and $0.15 \mathrm{~mm} / \mathrm{rev}$ were used to machine the samples (Table 1). The impact of depth of cut $\left(a_{p}\right)$ was kept fixed to $0.75 \mathrm{~mm}$. The cutting length of the Ti-6Al- $4 \mathrm{~V}$ bar was $60 \mathrm{~mm}$ per experiment. For each experiment, a new cylindrical bar of Ti-6Al-4 $\mathrm{V}$ having a $100 \mathrm{~mm}$ length and $60 \mathrm{~mm}$ diameter was used. Chemical composition of the specified alloy is present in Table 2.

\subsection{Cooling modes}

In order to evaluate the cooling/lubrication effects, dry, $\mathrm{LN}_{2}$ and hybrid $\mathrm{LN}_{2}+\mathrm{MQL}$ conditions were applied at the cutting zone. The dry machining experiments were performed without using any type of cutting fluid and cooling conditions. In $\mathrm{LN}_{2}$ cooling, the commercially

Table 1

Process parameters and other details.

\begin{tabular}{cl}
\hline $\begin{array}{c}\text { Machining } \\
\text { conditions }\end{array}$ & Levels \\
\hline $\begin{array}{c}\text { Cutting } \\
\text { speed }\end{array}$ & $100,125,150 \mathrm{~m} / \mathrm{min}$ \\
Feed rate & $0.10,0.125,0.150 \mathrm{~mm} / \mathrm{rev}$ \\
$\begin{array}{c}\text { Depth of } \\
\text { cut }\end{array}$ & $0.75 \mathrm{~mm}$ \\
$\begin{array}{c}\text { Cutting } \\
\text { tool }\end{array}$ & $\begin{array}{l}\text { CNGA } 120408 \text { rhombic shape having Nose radius } 0.8 \mathrm{~mm} \text {, approach } \\
\text { Cooling } \\
\text { mode }\end{array}$ \\
dry, $\mathrm{LN}_{2}$ and hybrid $\mathrm{LN}_{2}+\mathrm{MQL}$ conditions \\
\end{tabular}

Table 2

Chemical composition of Ti-6Al-4 V alloy used in this work.

\begin{tabular}{llllll}
\hline Titanium & Aluminum & Vanadium & Iron & Oxygen & Carbon \\
\hline $89.9 \%$ & $5.8 \%$ & $4 \%$ & $0.25 \% \max$ & $0.2 \% \max$ & $0.3 \% \max$ \\
\hline
\end{tabular}

available carrier gas with 999\% purity was delivered with the help of self - pressurized Dewar cylinder (Capacity of $50 \mathrm{~L}$ ). In hybrid $\mathrm{LN}_{2}+\mathrm{MQL}$ cooling condition, the liquid nitrogen gas was combined with the vegetable oil assisted MQL spray. The flow rate was fixed at $200 \mathrm{ml} / \mathrm{h}$ whereas, the liquid nitrogen flow rate used was $0.5 \mathrm{~L} / \mathrm{min}$. The nozzle of the MQL system was kept $25 \mathrm{~mm}$ away from the tool cutting edge.

\subsection{Experimental setup and response measurement}

A complete experimental setup contains a CNC turning center having a $7.5 \mathrm{~kW}$ of motor power. The cutting tools were tungsten carbide coated tools (CNGA 120408). The arithmetic surface roughness i.e., $R a$ was measured using Mitutoyo SJ-301 roughness tester by following ISO 4287 standards. The readings were recorded on three different locations of workpiece and the average reading has been selected for analysis. The cutting temperature was determined using an infrared camera FLUKE make. The thermal images were analyzed using the 'SmartView 4.0' software. The main cutting forces were recorded using three dimensional Kistler dynamometer. Dynoware software was used to collect forces data to get mean and force components. Moreover, the energy consumption was recorded with the online monitoring power measurement device i.e., Fluke make, energy analyzer during the cutting operation. The flow diagram of current work is shown in Fig. 2 and complete methodology adopted in the present work is portrayed in Fig. 3.

\section{Results and discussion}

The performance measures under dry, $\mathrm{LN}_{2}$ and $\mathrm{LN}_{2}$ plus MQL assisted machining at varying cutting parameters have been reported in this section Table 3 underscores the experimental design used in the current work for all cooling conditions. Each cooling condition,

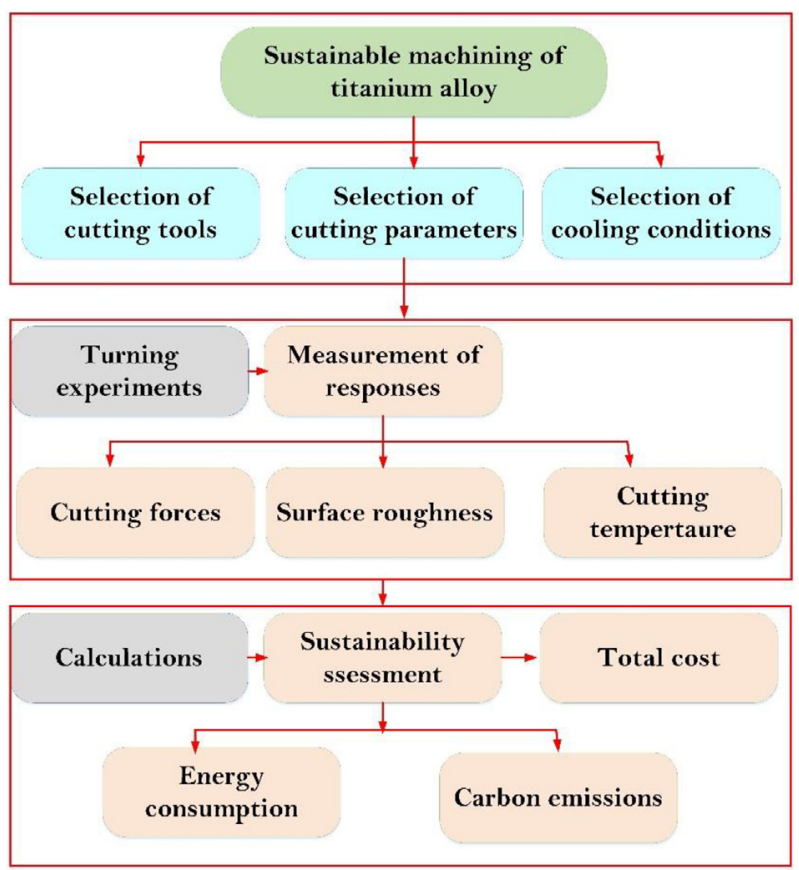

Fig. 2. Flow diagram of the current research work. 


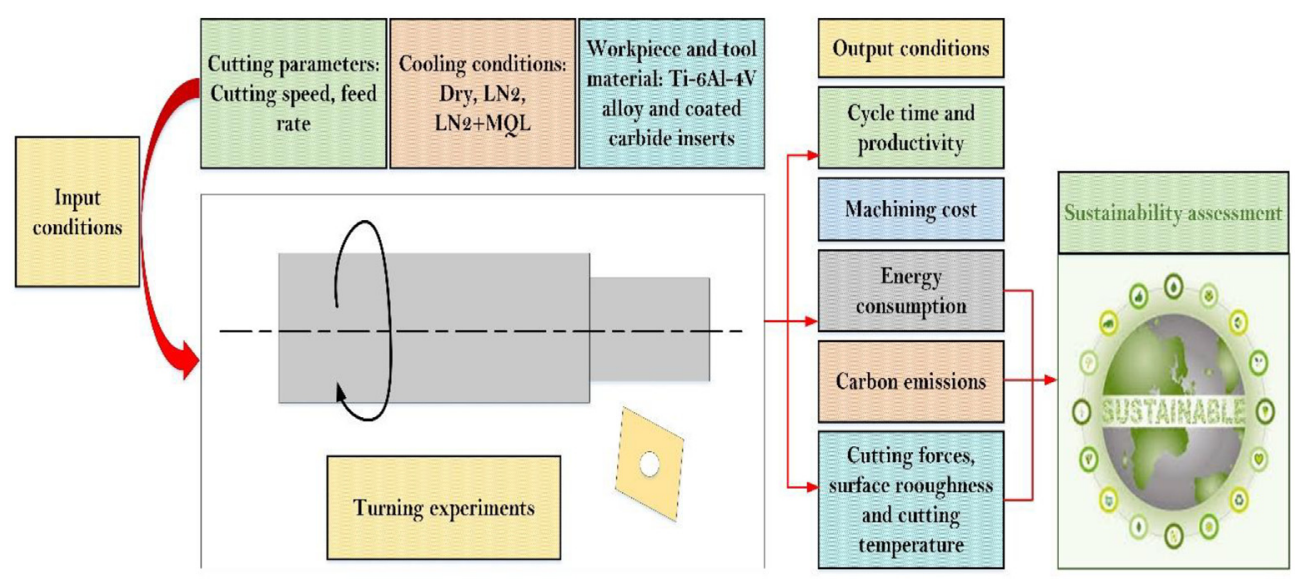

Fig. 3. Complete methodology adopted in the current work.

total no. of 9 experiments were performed by following the experimental design of Table 3.

\subsection{Total cycle time and productivity}

The total cycle time $\left(T_{T C T}\right)$ is used to compute the productivity and machining efficiency of the process. Total cycle time comprises of time at various stages of machining operation and is evaluated using Eq. (1):

$T_{T C T}=T_{\text {stdby }}+T_{c t}+T_{c u t}+T_{\text {air }}$

where, $T_{\text {stdby }}$ is standby time in seconds, $T_{c t}$ is tool changing time which depends upon tool life and time required to change the tool, $T_{c u t}$ is the cutting time in seconds and $T_{\text {air }}$ is the air cutting time in seconds. In the part production by machining operations, total machining time is the critical factor that directly affects productivity. From Fig. 4 it is indicated that increased machining time has led to reduction in number of parts produced within $8 \mathrm{~h}$ of operation and hence process productivity. Machining operators commonly use the way to change cutting parameters as the simplest way to set total machining times. For this reason, looking at the impact of cutting speed on the total cyclic time, it decreased by $22.98 \%, 30.71 \%$ and $21.07 \%$ under dry, $\mathrm{LN}_{2}$ and $\mathrm{LN}_{2}+\mathrm{MQL}$, respectively. Likewise, total cyclic time reduced by $13.46 \%, 18.43 \%$ and 14.03 respectively with rising feed rate. On the other hand, although the same cutting parameters are used in each sustainable cooling/lubrication environments, a noticeable difference in total machining times (hence productivity) has been observed. Here, the progress in total cycle time provided by $\mathrm{LN}_{2}$ and $\mathrm{LN}_{2}+\mathrm{MQL}$ was noted to be $29.01 \%$ and $34.21 \%$ respectively in comparison with dry turning. This is due to the shorter handling/replacement time of the cutting tool (tool change per cut) in $\mathrm{LN}_{2}+\mathrm{MQL}$ in comparison with $\mathrm{LN}_{2}$, and especially dry

Table 3

Experimental design used in the current work.

\begin{tabular}{llll}
\hline $\begin{array}{l}\text { Experimental } \\
\text { No. }\end{array}$ & $\begin{array}{l}\text { Cutting speed } \\
(\mathrm{m} / \mathrm{min})\end{array}$ & $\begin{array}{l}\text { Feed rate } \\
(\mathrm{mm} / \mathrm{rev})\end{array}$ & Depth of cut $(\mathrm{mm})$ \\
\hline 1 & 100 & 0.1 & 0.75 \\
2 & 100 & 0.125 & 0.75 \\
3 & 100 & 0.15 & 0.75 \\
4 & 125 & 0.1 & 0.75 \\
5 & 125 & 0.125 & 0.75 \\
6 & 125 & 0.15 & 0.75 \\
7 & 150 & 0.1 & 0.75 \\
8 & 150 & 0.125 & 0.75 \\
9 & 150 & 0.15 & 0.75 \\
\hline
\end{tabular}

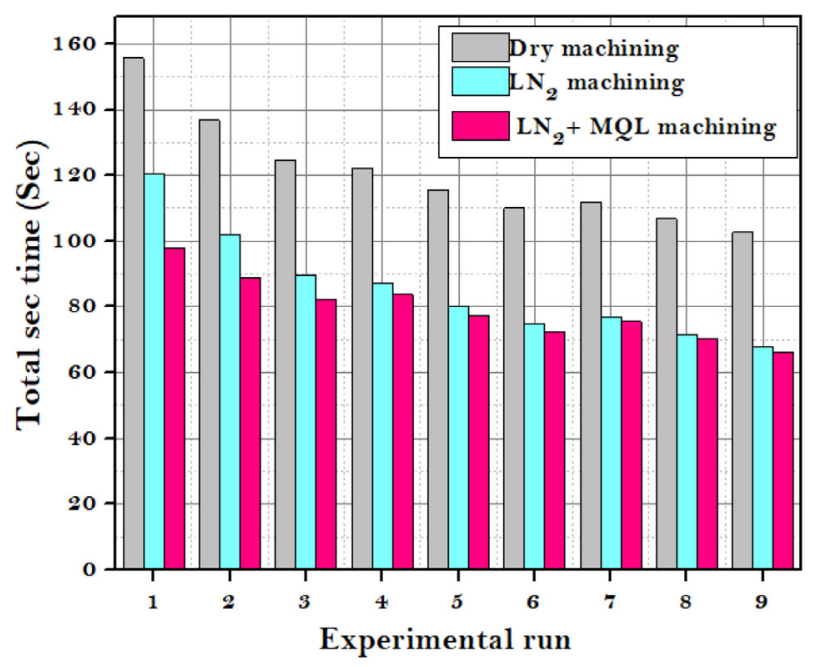

(a)

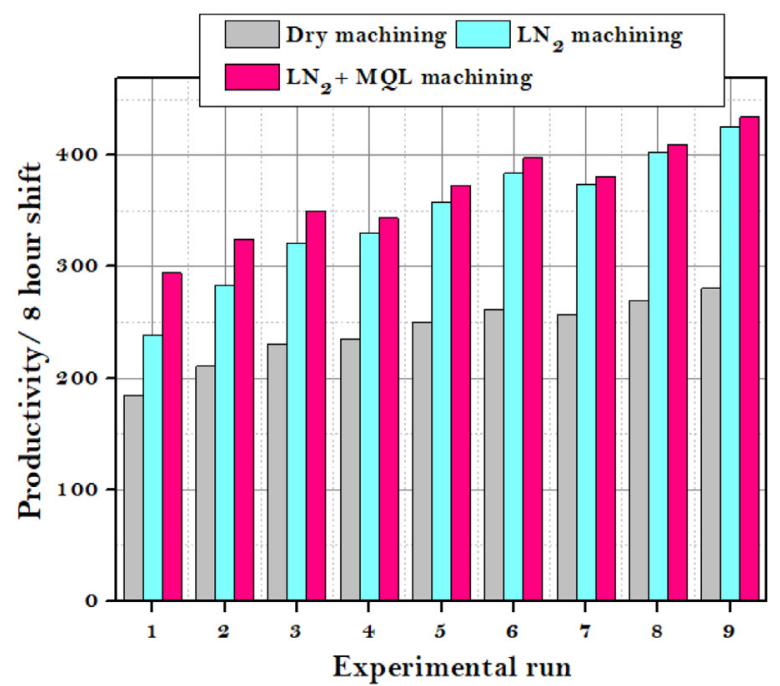

(b)

Fig. 4. (a) Total cycle time and (b) Productivity with respect to each experimental run

machining. In machining under $\mathrm{LN}_{2}$ plus MQL, the delay of tool wear, even a little, has significantly extended tool life. This has reduced the time required to replace the tool with a new one, resulting in less overall 


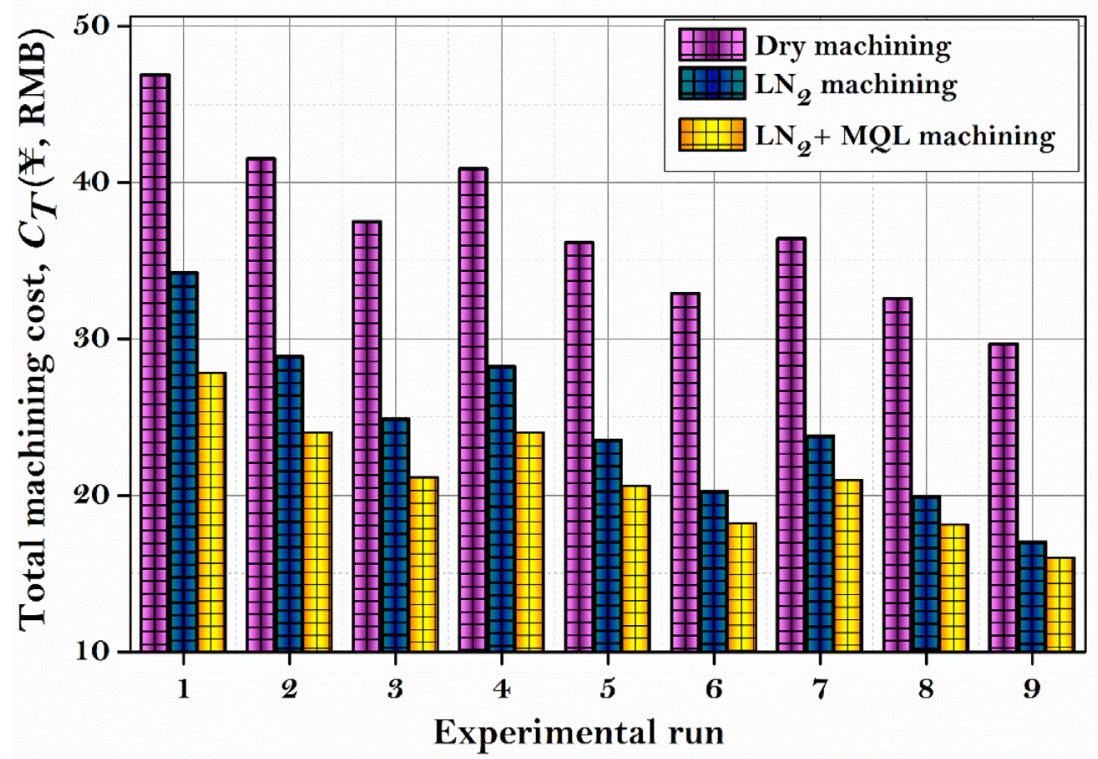

Fig. 5. Total machining cost values under dry, $\mathrm{LN}_{2}$ and $\mathrm{LN}_{2}+\mathrm{MQL}$ environments for different experimental runs

machining time. The effectiveness of $\mathrm{LN}_{2}$ plus MQL machining support in extending tool life and thermo-mechanical and physical mechanisms that assist this during cutting have been deliberated comprehensively in work by $[17,27]$.

\subsection{Total machining cost}

Achieving economic machining process is certainly one of the principle strategy to promote sustainable production. To ensure this, an indepth analysis of the total cost from the beginning to the end of the machining process is essential. The total machining cost $\left(C_{T}\right)$ comprises of energy (electricity) consumption cost $\left(C_{e}\right)$, overhead cost $\left(C_{o}\right)$, cutting insert cost $\left(C_{t}\right)$, coolant cost $\left(C_{c}\right)$ and coolant disposal cost $\left(C_{d}\right)$ which is described by Eq. (2).

$C_{T}=C_{e}+C_{o}+C_{t}+C_{c}+C_{d}$

Fig. 5 demonstrates the total machining cost for various experimental runs against different machining environments viz., dry, $\mathrm{LN}_{2}$ and $\mathrm{LN}_{2}+\mathrm{MQL}$. The least total machining cost has been observed in the ninth experimental run viz., cutting speed of $150 \mathrm{~m} / \mathrm{min}$ and feed rate of $0.15 \mathrm{~mm} / \mathrm{rev}$ under all machining environments. With regard to machining environments, $\mathrm{LN}_{2}$ plus MQL is superior to $\mathrm{LN}_{2}$ and dry turning. When the effective cooling medium is combined with the most appropriate selection of cutting parameters during the cutting process, it can be concluded that the total processing cost can be reduced by up to $65.84 \%$ as compared with dry machining in this experimental design. The details for the cost components leading to this situation are examined in the following sub-sections.

\subsubsection{Energy consumption cost, Ce ( $¥)$}

Machine tools employed in the manufacturing industry are responsible for consuming a significant portion of the total energy supplied worldwide. Due to the high unit energy price, energy consumption throughout production is a vital index that determines the total cost of the product. The lowering in energy consumption not only reduces carbon footprints, but also enables companies to meet their environmental obligations, as well as to reduce machining costs. Therefore, analysis of the energy demands of the machine tools in different machining parameters and environments is a must to ensure sustainability. The electricity consumption cost by the machine tool is dependent upon machining time for which machine tool is used, spindle motor power and unit energy cost. $C_{e}$ can be described by the following relation:

$C_{e}=C_{\text {cut }}+C_{\text {ncut }}$

$C_{e}=\frac{\text { Unit Energy Cost }}{\eta \times 60 \times 1000} \times t_{m} \times($ cutting power + standby power $)$

where $C_{\text {cut }}=$ cutting energy cost, $C_{\text {ncut }}=$ machine standby cost.

where unit energy cost is $0.33 ¥ / \mathrm{kWhr}$ for an industrial site, $\eta$ is the machine efficiency (generally 85\%), cutting power of the machine tool is $3324 \mathrm{~W}(150 \mathrm{~m} / \mathrm{min})$ while machine standby power is about $1987 \mathrm{~W}$ (constant). While the machining time $t_{m}=\frac{\text { Length of cut+machining allowance }}{\text { feed ratexrpm }}$ determined for each experiment. According to Fig. 6, energy consumption cost account for $49.09 \%, 43.03 \%$ and $43.41 \%$ of the total cost under dry, $\mathrm{LN}_{2}$ and $\mathrm{LN}_{2}+\mathrm{MQL}$, respectively. As it is noticed, energy consumption cost has the largest share in total cost. Since the energy consumption of machine tools is directly related to the machine's working time, the increased level of operation parameters can reduce the actual machining time and thus the energy consumption and its cost.

\subsubsection{Overhead cost, Co ( $¥)$ :}

The machining overhead cost consisted of operator cost $\left(C_{o p}\right)$, cost of lighting and $\operatorname{HVAC}\left(C_{L}\right)$, and machine depreciation cost $\left(C_{m}\right)$ as given the following relation:

Overhead $\operatorname{cost} C_{o}=C_{o p}+C_{L}+C_{m}$

where operator cost ' $C_{o p}=$ operator labor cost rate $(42 ¥ / \mathrm{hr}) \times$ machine time $\left(t_{m}\right) \times$ number of workers' is the operating cost during the machining. Similarly, the cost of lighting $C_{L}=$ (cost of lighting $0.3 \mathrm{~kW}$ and HVAC of $8 \mathrm{~kW}) \times$ unit energy cost $(0.33 ¥ / \mathrm{kWhr}) \times$ machining time $\left(t_{m}\right) / 60$. The machine depreciation cost is determined as:

$$
\begin{aligned}
C_{m} & =\frac{(\text { Initial cost }- \text { Salvage value }) \times \text { machining time }}{\text { Useful life }} \\
& =\frac{(7,50,000-50,000) \times t_{m}}{10 y r s \times 250 \text { days } / y r \times 8 h r / \text { day }}
\end{aligned}
$$

Accordingly, it can be deduced from Fig. 6 the share of the overhead cost, with a sum of above mentioned components such as operator cost, 


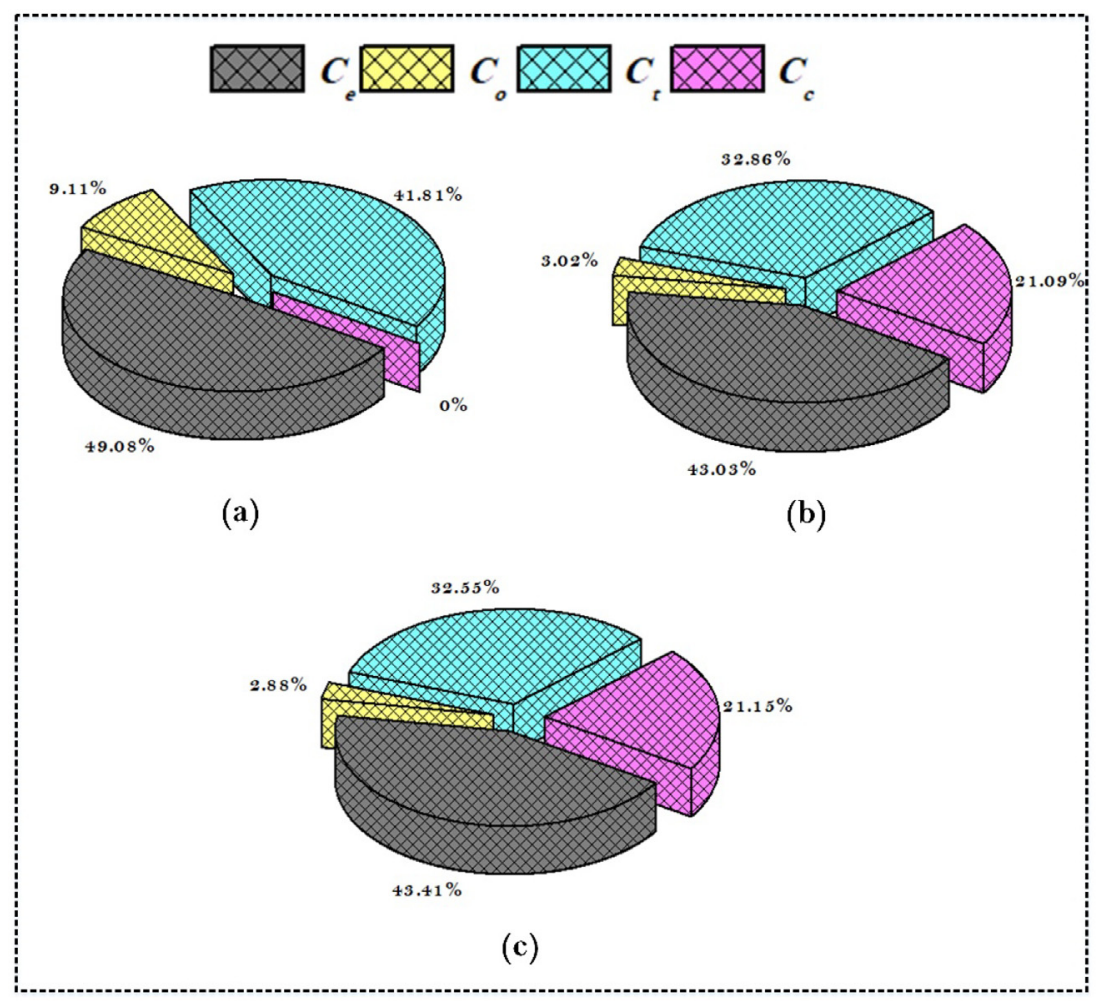

Fig. 6. Total cost sharing under different cooling conditions (a) Dry (b) $\mathrm{LN}_{2}$ (c) $\mathrm{LN}_{2}+\mathrm{MQL}$

cost of lighting and HVAC and machine depreciation cost, in the total cost per unit part is $9.11 \%, 3.02 \%$ and $2.88 \%$ for dry, $\mathrm{LN}_{2}$ and $\mathrm{LN}_{2}+\mathrm{MQL}$ respectively.

\subsubsection{Tool cost, $C t$ ( $¥)$}

The desire to machine the materials having superior features at higher speeds and in less time encourages the advancement of cutting tool technology day by day. However, this situation also reflects the cutting insert production costs of manufacturers, and consequently to the cutting insert sales price. During the mass production of parts in machine tools, a substantial part of the total cost is the insert cost. Therefore, in order to reduce this to reasonable levels, a number of measures such as reducing cutting parameters and using coolant are taken by operators. In addition, when the cutting insert attaining $0.3 \mathrm{~mm}$ wear value $\left(V B_{\max }=0.3 \mathrm{~mm}\right)$, it can be reground and can be sold at lower price. The insert original price was $85 ¥$ and resale value after ground was $25 ¥$. Therefore, the net cutting insert cost can be found as follows:

$C_{t}=\frac{\text { insert price }- \text { resale price }}{\text { tool life }} \times$ machining time

Fig. 6 illustrates the proportion of tool cost to total cost. According to this, cutting tool costs account for $41.81 \%, 32.86 \%$ and $32.55 \%$ of total cost in machining under dry, $\mathrm{LN}_{2}$ and $\mathrm{LN}_{2}+\mathrm{MQL}$, respectively. As can be seen, tool cost has the second largest share after energy consumption cost.

\subsubsection{Coolant cost, Cc ( $¥)$}

In machining operations conducted under petroleum-based conventional fluid, coolant cost is responsible for $15-17 \%$ of final part cost [28]. It has been noted that costs associated with cutting fluids in such operations can be higher than the costs of cutting tools [29]. It is therefore paramount to eliminate or minimize cutting fluids in order to ensure sustainability of machining process. The cooling/lubrication techniques used in this study, being harmless, economic and environmental friendly, provide advantages over traditional methods. The cost of MQL lubricant is dependent upon the cost per liter (67¥/liter), flow rate $(0.0033 \mathrm{l} / \mathrm{min})$ and machining time. Similarly, the cost of the liquid nitrogen can be determined by cost per liter ( $50 ¥ / \mathrm{kg})$, flow rate $(0.2 \mathrm{~kg}$ / min) and machining time.

$\begin{aligned} \text { Coolant cost } C_{c}= & \text { coolant /lubricant cost } \times \text { flow rate } \\ & \times \text { machining time }\end{aligned}$

Fig. 6 exhibits that the cooling cost has a share of $21.09 \%$ and $21.15 \%$ within the total cost for $\mathrm{LN}_{2}$ and $\mathrm{LN}_{2}+\mathrm{MQL}$, respectively. In an operation using liquid nitrogen, the reason for the higher share of coolant costs in the total cost is undoubtedly due to its higher consumption per unit time and elevated unit 's cost. The comparative cost under $\mathrm{LN}_{2}$ and $\mathrm{LN}_{2}+\mathrm{MQL}$ is provided in Table 4.

\subsubsection{Disposal cost}

Continuous use of water-based metalworking fluids (conventional cooling) is impossible, due to problems such as degradation, contamination, bacterial growth, filter failure and increased pump power arising from its excessive use. Therefore, these liquids have a limited lifetime and must be disposed of in an environmentally friendly manner when they reach the end of their lifetime. On the other hand, chips resulting from cutting under MQL are almost dry and can be recycled to provide additional income without the need for any cleaning procedures. Since the lubricant is completely consumed, no disposal is required and no extra equipment is required for fluid recovery. The same thing can be said about using $\mathrm{LN}_{2}$ as in MQL. Since the cryogenic liquid completely evaporates at ambient temperature, the chips and workpiece are completely dry. Therefore, the $\mathrm{LN}_{2}$ and $\mathrm{LN}_{2}+\mathrm{MQL}$ as well as dry cutting have no disposal cost. 
Table 4

Cost description and breakdown of costs under $\mathrm{LN}_{2}$ and $\mathrm{LN}_{2}+\mathrm{MQL}$ conditions.

\begin{tabular}{|c|c|c|}
\hline $\begin{array}{l}\text { Cost type } \\
\text { description }\end{array}$ & Breakdown of cost & $\begin{array}{l}\text { Cost sharing } \\
\text { values }\end{array}$ \\
\hline $\begin{array}{l}\text { Cost of energy } \\
\text { consumption, } C_{e}\end{array}$ & $\begin{array}{l}\text { Energy consumed by machine tool } \\
\text { for cutting material } \\
\text { Energy consumed by the machine } \\
\text { standby }\end{array}$ & $\begin{array}{l}\text { Dry machining, } \\
C_{e}=49.08 \% \\
\mathrm{LN}_{2} \text { machining, } \\
C_{e}=43.03 \% \\
\mathrm{LN}_{2}+\mathrm{MQL} \\
\text { machining, } \\
C_{e}=43.41 \%\end{array}$ \\
\hline Overhead cost, & $C_{o p}$ is the operator cost, $42 ¥ / \mathrm{hr}$. & Dry machining, \\
\hline$C_{o}=C_{o p}+C_{L}+C_{m}$ & & $C_{o}=9.11 \%$ \\
\hline$C_{L}=$ Lighting and & $C_{m}$ is the depreciation cost, & $C_{o}=3.02 \%$ \\
\hline HVAC cost & Machine purchase cost $=7,50,000 ¥$, & $\mathrm{LN}_{2}+\mathrm{MQL}$ \\
\hline $\begin{array}{l}C_{m}=\text { Machine } \\
\text { depreciation cost }\end{array}$ & $\begin{array}{l}\text { salvage value }=50,000 ¥ \text {, } \\
\text { Life }=10 \text { years, } \\
\text { Annual working days }=250 \text { days }\end{array}$ & $\begin{array}{l}\text { machining, } \\
C_{o}=2.88 \%\end{array}$ \\
\hline $\begin{array}{l}\text { Cost of tool/cutting } \\
\text { insert, } C_{t}\end{array}$ & New insert cost, Resale value & $\begin{array}{l}\text { Dry machining, } \\
C_{t}=41.81 \% \\
\mathrm{LN}_{2} \text { machining, } \\
C_{t}=32.86 \% \\
\mathrm{LN}_{2}+\mathrm{MQL} \\
\text { machining, } \\
C_{t}=32.55 \%\end{array}$ \\
\hline Cost of coolant, $C_{c}$ & MQL lubricant cost/l = 67¥/liter & Dry machining, \\
\hline$C_{c}=\mathrm{MQL}$ & MQL flow rate $=0.0033 \mathrm{l} / \mathrm{min}$ & $C_{c}=$ No coolant \\
\hline$C_{c}=\mathrm{LN}_{2}$ coolant cost & $\begin{array}{l}\mathrm{LN}_{2} \text { coolant cost } / \mathrm{kg}=50 ¥ / \mathrm{kg} \\
\mathrm{LN}_{2} \text { flow rate }=0.2 \mathrm{~kg} / \mathrm{min}\end{array}$ & $\begin{array}{l}\mathrm{LN}_{2} \text { machining, } \\
C_{c}=21.09 \% \\
\mathrm{LN}_{2}+\mathrm{MQL} \\
\text { machining, } \\
C_{c}=21.15 \%\end{array}$ \\
\hline
\end{tabular}

\subsection{Energy consumption analysis}

An analysis of the energy consumption of a machine tool provides more information to the organization than the amount of electrical energy consumed. Some of the factors that necessitates the analysis of energy consumption are as follows:

i) Almost half of the production costs are due to energy costs

ii) The world is always in search for new energy sources and

iii) Carbon emissions due to energy consumption damages natural environment (refer Fig. 7).
The energy consumption (Ec) analysis as per the Eq. (7) was carried out to investigate an additional energy proficient cutting environment.

$E_{c}=\frac{F_{c}(N) \times V_{c}(\mathrm{~m} / \mathrm{min}) \times \text { Machining time }(\mathrm{min})}{1000}$

where $F_{c}$ is main cutting force $(N), V_{c}$ is cutting speed in $\mathrm{m} / \mathrm{min}$ and $E_{c}$ is in $\mathrm{kJ}$.

According to one estimate, industry shares around 31\% of all energy consumption and manufacturing sector is accountable for approximately $60 \%$ of the energy consumed by industry [30]. The share and importance of chip removal operations in manufacturing is significant. Zhao et al. [30] reported that energy efficiency is not at the desired level, since the energy used in real machining corresponds to only $15 \%$ of the total energy. Hence, reducing energy consumption on machine tools is vital to ensure sustainable production in machining operations. Fig. 8 demonstrates energy consumption in turning of Ti-6al-4v alloy under dry, $\mathrm{LN}_{2}$ and $\mathrm{LN}_{2}$ plus $\mathrm{MQL}$ at different operation parameters viz., cutting speed: 100,125 and $150 \mathrm{~m} / \mathrm{min}$ and feed rate: $0.1,0.125$ and $0.15 \mathrm{~mm} / \mathrm{rev}$. With decreasing cutting parameters (for both feed and cutting speed) it is possible to realize the net reduction in energy consumption. The average reduction in energy consumption was found to be $25.05 \%, 23.55 \%$ and $23.01 \%$ at lowest cutting speed in turning under dry, $\mathrm{LN}_{2}$ and $\mathrm{LN}_{2}+\mathrm{MQL}$, respectively. For decreased feed rate from 0.15 to $0.1 \mathrm{~mm} / \mathrm{rev}$, the percentage of decrease in energy consumption was calculated as 4.33, 9.44 and 7.95 in dry machining, $\mathrm{LN}_{2}$ and $\mathrm{LN}_{2}$ plus $\mathrm{MQL}$, respectively. The decline in energy consumed by machine tool after each cut is attributed to the decrease in operating speeds, reducing the chip removal per unit time. It was noticed that impact of lower cutting speed on energy consumption was more in comparison with influence of lower feed rate. The justification for this situation is the rise in the spindle speed with growing cutting speed, and it triggers the current absorbed by the motor to rotate faster. When a comparison is made between the cooling environments used, the $\mathrm{LN}_{2}$ plus MQL consumed around $15.89 \%$ and $3.07 \%$ less energy than dry and $\mathrm{LN}_{2}$ machining, respectively. It is stated that $\mathrm{LN}_{2}$ has a kind of favorable boundary lubricating features [31]. Due to the high temperature under dry cutting, there is a strong adhesion/bonding desire on the tool and chip interface, and thanks to the $\mathrm{LN}_{2}$, lower temperature reduces the adhesion between the interacting surfaces. This makes the material harder and less sticky, resulting in

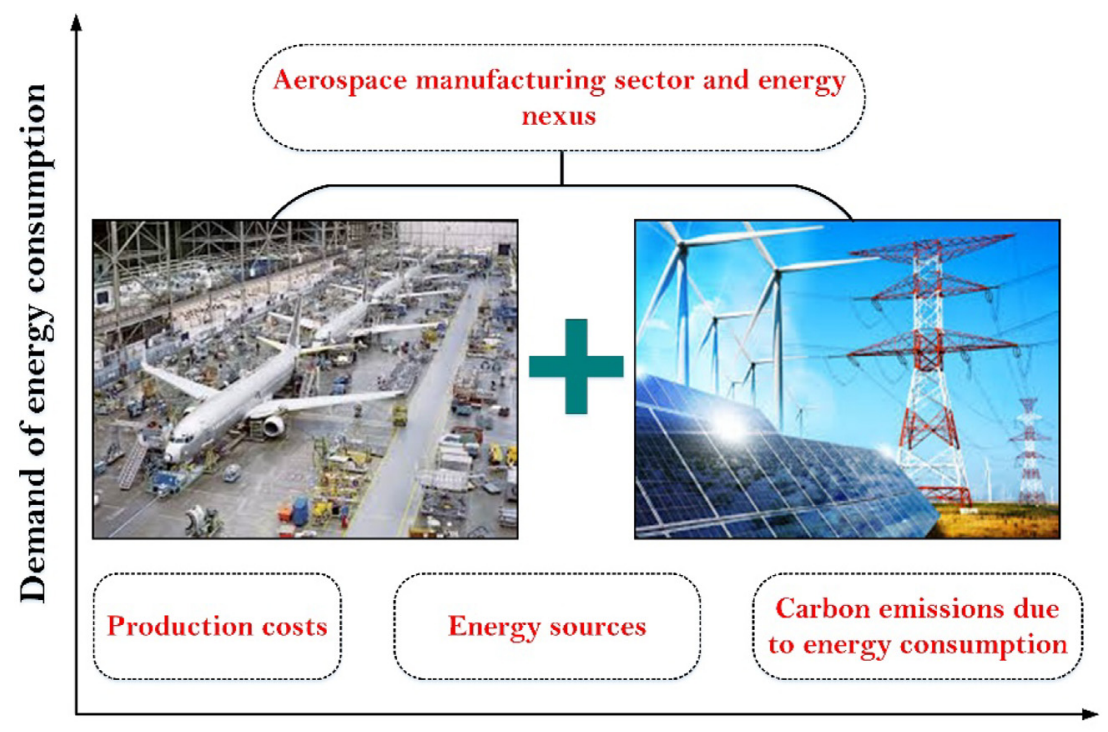

Fig. 7. Factors affecting the energy consumption. 


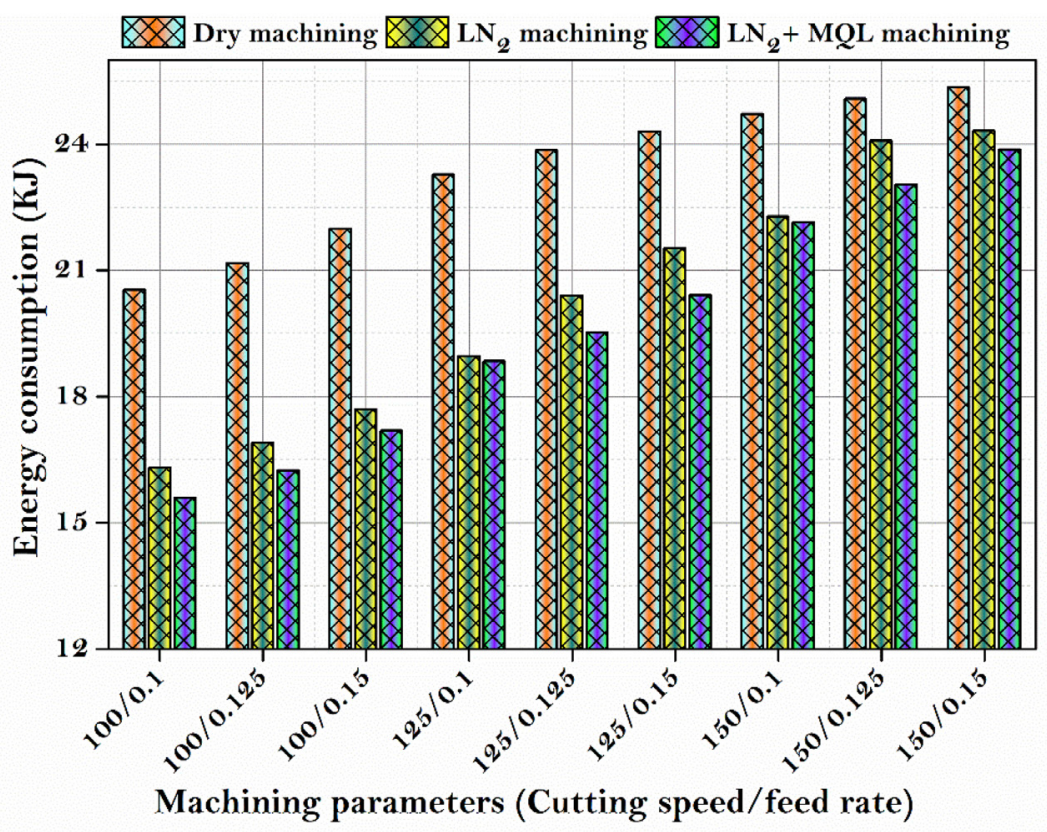

Fig. 8. Energy consumption values under dry, $\mathrm{LN}_{2}$ and $\mathrm{LN}_{2}+\mathrm{MQL}$ environments at different experimental run

low friction [32]. In addition, the benefit of MQL is that oil droplets penetrate between the tool-workpiece-chip, thereby also reduce friction. The combination of MQL with the cryogenic liquid had a hybrid effect, thus providing a favorable result [27]. Reduced friction force with the employment of $\mathrm{LN}_{2}$ and $\mathrm{LN}_{2}$ plus MQL helped to reduce the power required during cutting. This was taken into account as the main reason for the further reduction of energy consumption with $\mathrm{LN}_{2}$ plus MQL machining.

\subsection{Carbon emissions analysis}

Environmental deterioration has started to be felt more prominently after the industrial revolution as a consequence of the brisk growth in production and the high rate of fossil fuels being preferred as the energy input. The prevalent use of fossil fuels raised the density of greenhouse gases. This also posed a serious obstacle to the concept of low carbon economy because $\mathrm{CO}_{2}$ is the key factor causing the climate change amongst greenhouse gas emissions [33]. To reduce this, either the ratio of renewable energy sources in energy production should be increased or industrial activities that consume energy intensely should be analyzed in depth. In general, carbon emission is calculated with the help of Eq. (8):

$C_{e e}=E_{c} * F_{e}$

where, $C_{e e}$ is carbon emissions produced in $\mathrm{kg}-\mathrm{CO}_{2}, E_{c}$ is electrical energy consumption and $F_{e}$ is the carbon emission factor (0.4228) used in case of electric consumption. In the current investigation, the $\mathrm{CO}_{2}$ emissions released from the machine tools during the machining operations were investigated and the results are presented in Fig. 9. Since carbon emissions are directly related to energy use, a trend similar to the results obtained from the energy consumption section has also been observed in this section. Actually, the maximum reduction in carbon emissions can be achieved by choosing cutting parameters in harmony under the most suitable cooling medium. That is, $10.71 \mathrm{~kg}-\mathrm{CO} 2$ emissions derived from machine tool at $150 \mathrm{~m} / \mathrm{min}$ cutting speed and $0.15 \mathrm{~mm} / \mathrm{rev}$ feed rate under dry machining can be reduced to $6.58 \mathrm{~kg}-\mathrm{CO}_{2}$ emissions with $100 \mathrm{~m} / \mathrm{min}$ cutting speed and $0.1 \mathrm{~mm} / \mathrm{rev}$ feed under $\mathrm{LN}_{2}+\mathrm{MQL}$ assisted machining. This means a $38.56 \%$ reduction in $\mathrm{CO}_{2}$ emissions with optimum processing conditions can be achieved.

\subsection{Machinability investigations}

The machinability of engineering materials can be determined by wide variety machining characteristics such as chip formation, tool wear, surface quality of the machined work-material, cutting temperature and cutting forces. In this study, machining behaviors viz., surface roughness, cutting temperature and main cutting force were investigated and deliberated in sub-sections as follows:

\subsubsection{Surface roughness}

Surface roughness under dry, $\mathrm{LN}_{2}$ and $\mathrm{LN}_{2}$ plus MQL assisted machining at different conditions have been portrayed in Fig. 10. On comparing the right, middle and left panes (i.e., dry, $\mathrm{LN}_{2}$ and $\mathrm{LN}_{2}$ plus $\mathrm{MQL}$ ) in the graph, it was depicted that the surface roughness produced under $\mathrm{LN}_{2}+\mathrm{MQL}$ is lesser than dry and $\mathrm{LN}_{2}$ turning. Considering the average of all roughness results measured under three different environments, the surface roughness achieved with $\mathrm{LN}_{2}+\mathrm{MQL}$ based machinability is $32.84 \%$ and $20.34 \%$ lower than dry and $\mathrm{LN}_{2}$ machining, respectively. In the previous study by [34], the role of cryogenic cooling on surface roughness was explained by three basic phenomena as follows: (i) $\mathrm{LN}_{2}$ assisted cutting diminishes tool wear compared to dry machining of hard-to-machine materials such as titanium alloys. (ii) Cryogenic assisted machining helps to preserve the ideal tool geometry for a long time by reducing or eliminating possible Built-up-edge (BUE) formation. (iii) $\mathrm{LN}_{2}$ machining prevents possible distortion of the workpiece due to the high temperature effect. Moreover, it was stated by Gupta et al. [35] that due to the elevated temperature effect in dry cutting, the chips attached loosely to the surface were eliminated with $\mathrm{LN}_{2}$ and this contributed towards improvement of the surface roughness. With $\mathrm{LN}_{2}$, although the roughness has improved to a certain level, its alliance with MQL has created a double effect, providing a better quality surface. Base fluid MQL's performance on surface roughness has been presented in many previously published studies [36,37]. The basic mechanism here is that the deep penetration of oil droplets with the compressed air into the cutting zone not only reduces friction between the contacting elements but also lowers the temperature. Researchers $[38,39]$ who obtained similar results stated that, on the one hand, the need to cool the cutting zone with cryogenic was met, on the other hand, MQL contributed in reducing friction by lubricating the contacting 


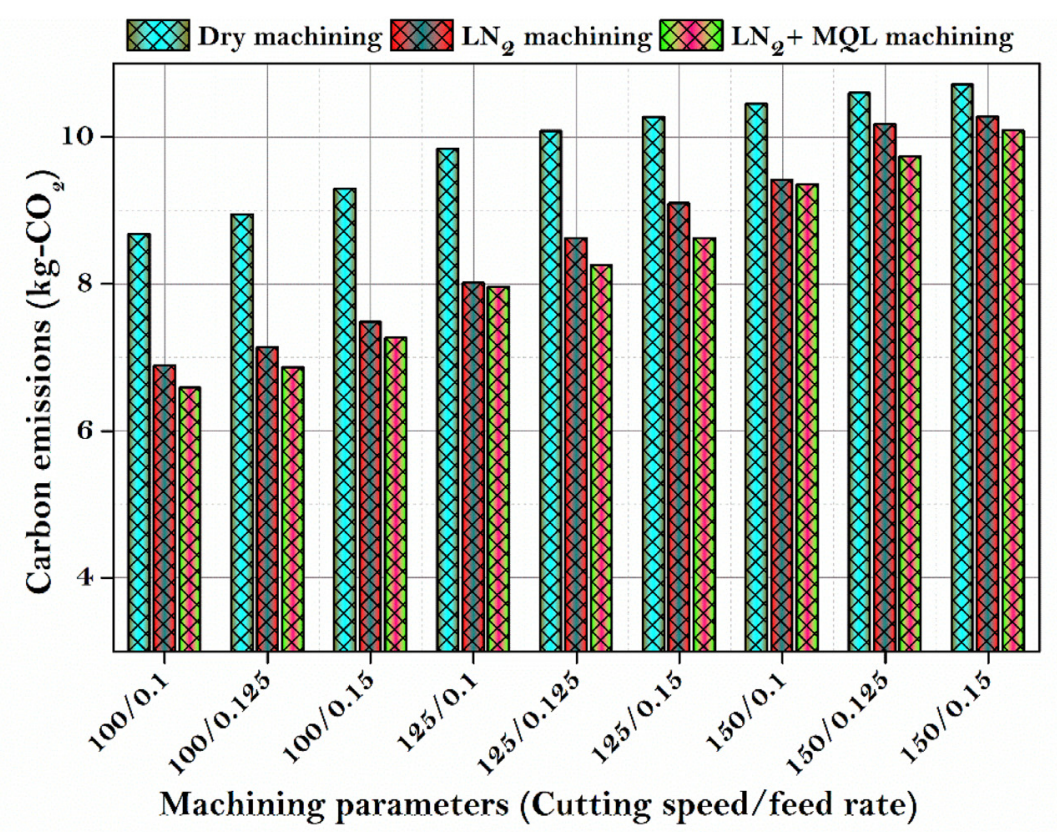

Fig. 9. Carbon emission values under dry, $\mathrm{LN}_{2}$ and $\mathrm{LN}_{2}+\mathrm{MQL}$ environments at different experimental run

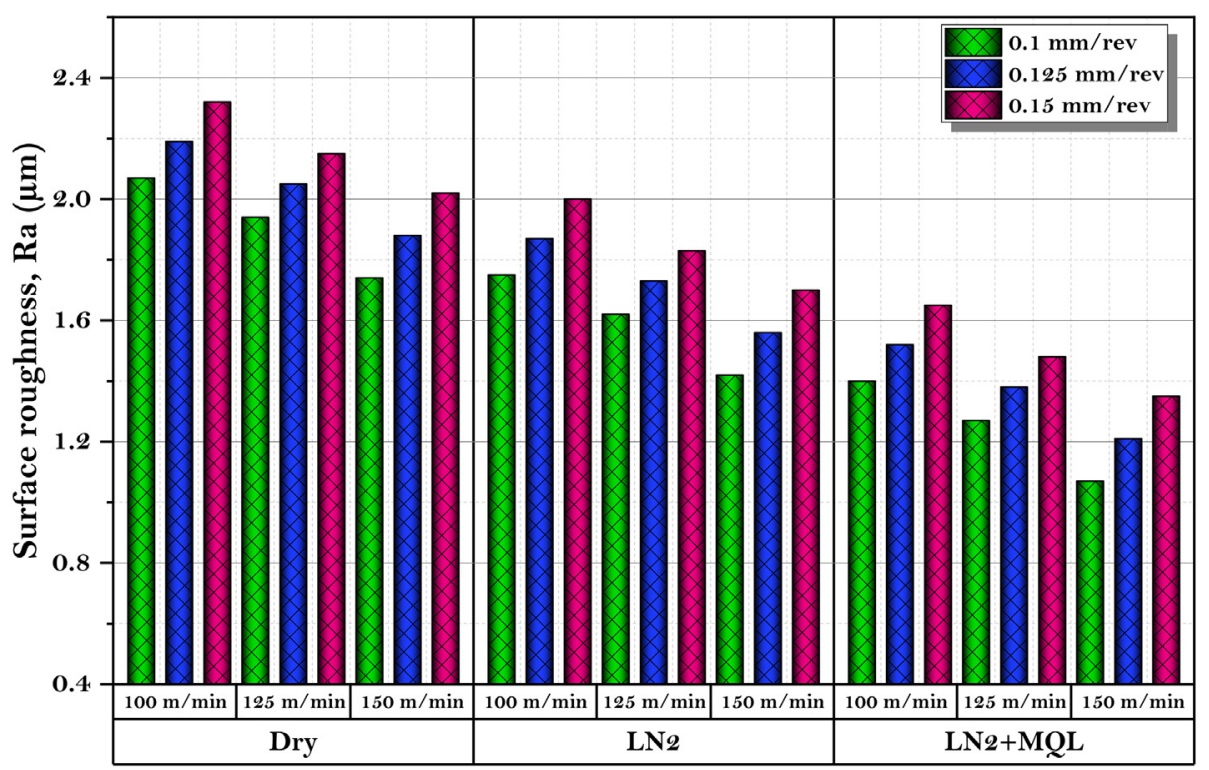

Fig. 10. Surface roughness values under dry, $\mathrm{LN}_{2}$ and $\mathrm{LN}_{2}+\mathrm{MQL}$ environments at different experimental run.

surfaces. It is divulged from Fig. 10 that the surface quality is enriched with increasing cutting speed while opposite effect has occurred with increasing feed rate, and the surface quality has deteriorated. The results are in line with the knowledge of the literature, and the details of this outcome have been discussed in previous studies $[38,40]$.

\subsubsection{Cutting temperature}

The results of cutting temperature under dry, $\mathrm{LN}_{2}$ and $\mathrm{LN}_{2}+\mathrm{MQL}$ environments at diverged cutting speed and feed rate are contrasted together in Fig. 11. It is obvious from the bar charts that the cutting temperature via $\mathrm{LN}_{2}+\mathrm{MQL}$ is reduced more as compare to $\mathrm{LN}_{2}$ and dry turning. When the average of all temperature results saved under three environments is computed, the cutting temperature of $\mathrm{LN}_{2}+\mathrm{MQL}$ and $\mathrm{LN}_{2}$ machining is lower by $43.77 \%$ and $40.16 \%$ than dry machining, respectively. In fact, it has been previously reported that pure-MQL was insufficient to lower the temperature in the cutting zone. But, as in this study, MQL's collaboration with a strong coolant like $\mathrm{LN}_{2}$ allowed it to penetrate the cutting zone temperature more effectively. There are few reasons behind effectiveness of this combination in lowering the temperature further. One of the reasons may be the additional heat absorption of $\mathrm{LN}_{2}+\mathrm{MQL}$ during the phase transition of the oil from solid to liquid and then perhaps to the gas [39]. Another reason could be that the cryogenic liquid cools the workpiece and tool surface, which prevents MQL oil drops from burning or evaporating away from the environment [35]. Lastly, while the need to cool the cutting zone with cryogenic was supplied, the MQL contributed in reducing friction by lubricating the contacting surfaces [38]. It is obvious from Fig. 11 that while the temperature rise accelerated with increasing cutting speed, 


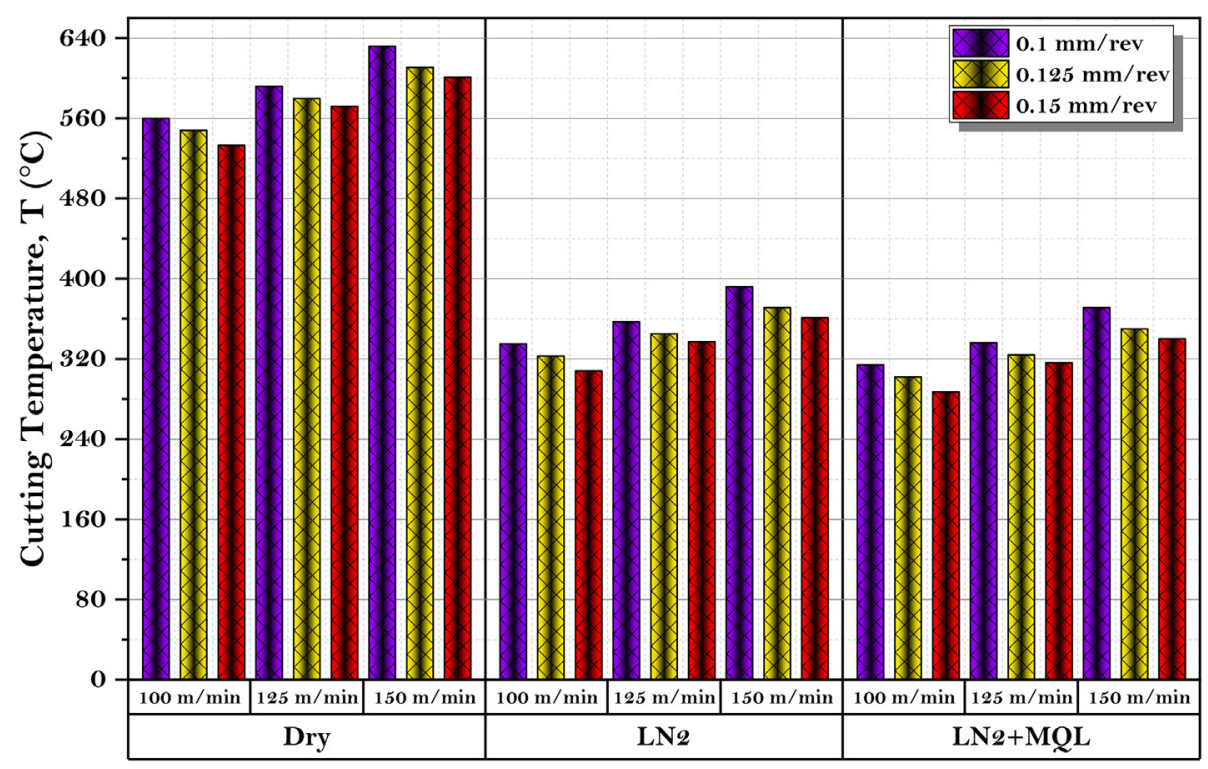

Fig. 11. Cutting temperature values under dry, $\mathrm{LN}_{2}$ and $\mathrm{LN}_{2}+\mathrm{MQL}$ environments at different experimental run.

the opposite situation has occurred with increasing feed rate, and the temperature has reduced. This result is in line with that reported in literature, and the details of the grounds have been discussed in previous studies $[41,42]$.

\subsubsection{Main cutting force}

The alteration in the main cutting force against different machining parameters under dry, $\mathrm{LN}_{2}$ and $\mathrm{LN}_{2}+\mathrm{MQL}$ assisted turning environments have been presented in Fig. 12. It is determined that the cutting force at dry turning is $27.97 \%$ and $36.67 \%$ higher than $\mathrm{LN}_{2}$ and $\mathrm{LN}_{2}+\mathrm{MQL}$ turning of Ti-6Al-4v alloy respectively. As the main reasons behind measuring less cutting force, thanks to cryogenic cooling with $\mathrm{LN}_{2}$ and $\mathrm{LN}_{2}$ plus MQL, the following justifications can be presented: (1) Deceleration of cutting tool wear due to reduced temperature; (2) Inhibition of BUE formation; (3) Oil droplets that penetrate between the tool and chip, reduce friction and therefore friction force. As for the influence of cutting parameters viz., cutting speed and feed rate, it can be said that the result drawn here is not a surprise and is in harmony with the literature knowledge [43].

\section{Sustainability assessment of process parameters}

The development of the relationship between environment and manufacturing processes is very important to address the sustainability aspects in terms of social, economic and environment. That's why the sustainability assessment of manufacturing processes is a very crucial topic and very useful to bridge the gap between a specific process and environment. In this work, five indicators i.e., energy consumption, carbon emissions, cutting forces, cutting temperature and surface roughness were considered to address the environmental nexus, as depicted in Fig. 13.

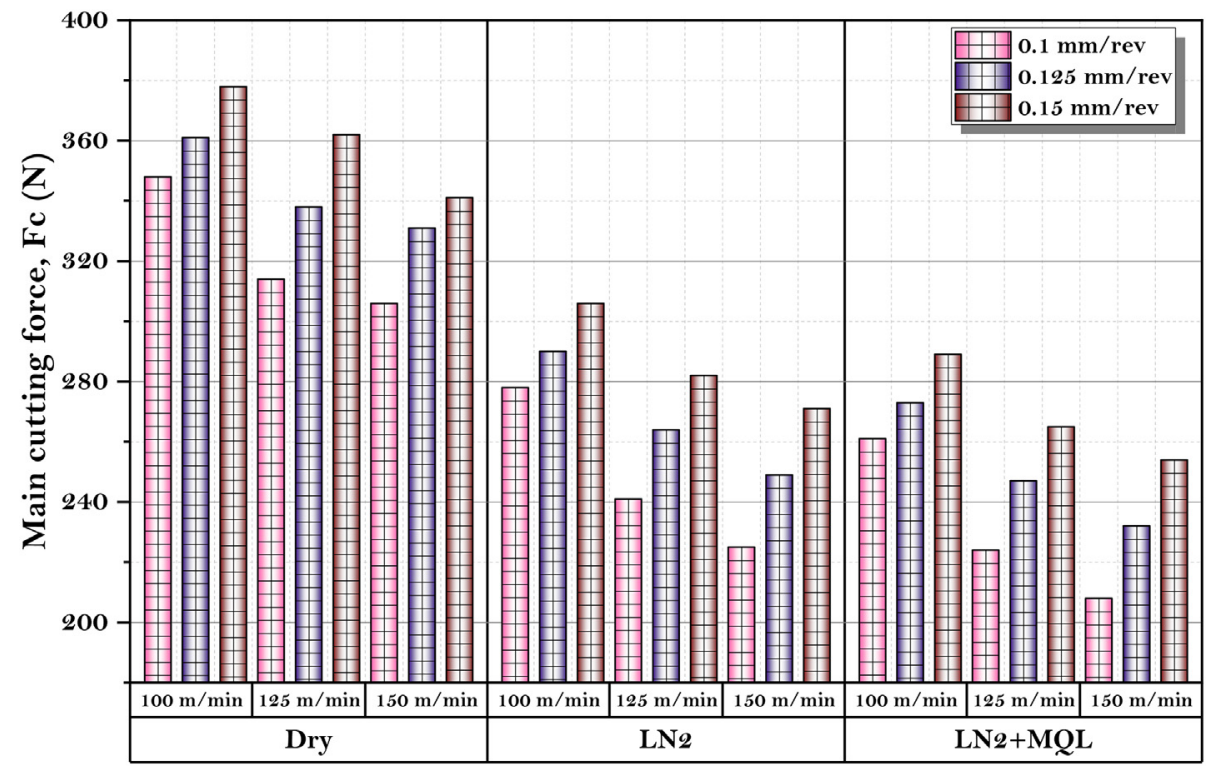

Fig. 12. Main cutting forces values under dry, $\mathrm{LN}_{2}$ and $\mathrm{LN}_{2}+\mathrm{MQL}$ environments at different experimental run 


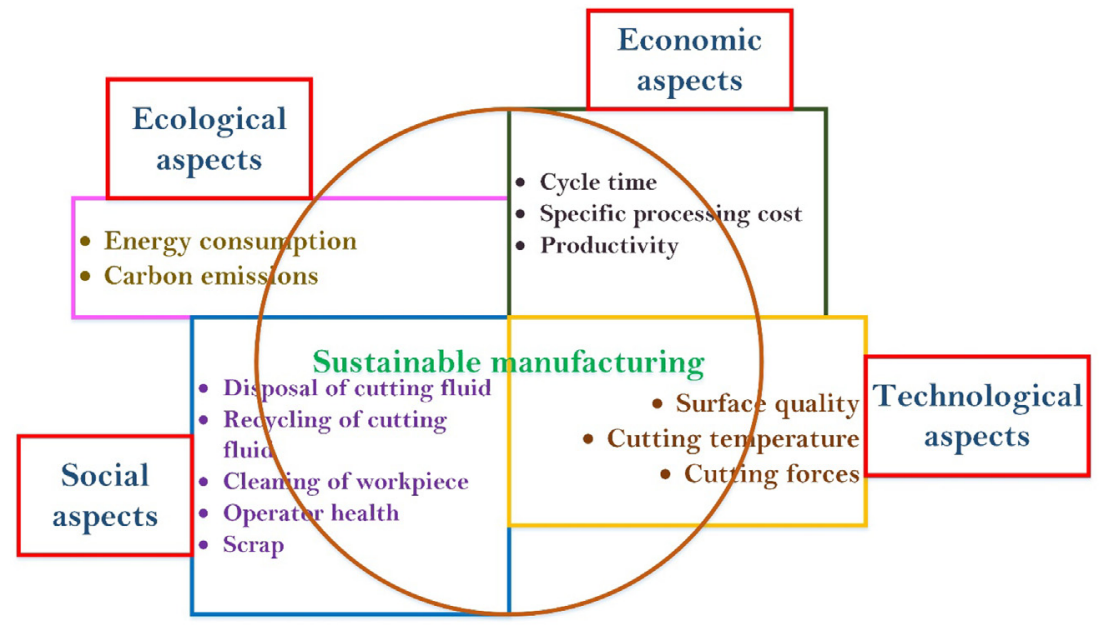

Fig. 13. Factors contributing in sustainable manufacturing.

The sustainability assessment process is often based on the comparisons of various conflicting criteria to consider the best available option from the given finite set. AHP-TOPSIS techniques were implemented for the sustainability assessment due to their widely used applications in complex decision-making. In this study, a total of 27 experiments under dry, $\mathrm{LN}_{2}$ and $\mathrm{LN}_{2}+\mathrm{MQL}$ environments were considered. To choose the best set from the nine available alternatives for respective machining processes, at first AHP method was implemented to compute the weights based on the decision-making criteria. For sustainability assessment, the decision-making criteria involved surface roughness ( $\mathrm{Ra})$, cutting temperature $(\mathrm{T})$, cutting force $(\mathrm{Fc})$, energy consumption and carbon emissions. To calculate pair-wise comparison matrix surface roughness, cutting temperature and cutting forces were given a score of 3 which corresponds to moderate importance, on the other hand, energy consumption and carbon emissions were given a score of 9 which corresponds to extreme importance, respectively. The scores were assigned with the aid of environmental importance. The pair-wise comparison matrix using AHP is shown below (Table 5). The steps used to calculate weights using AHP on machining data are reported in the work by [44].

Using pair-wise comparison matrix, the following weights were computed using AHP corresponding to surface roughness (Ra), cutting temperature $(\mathrm{T})$, cutting force $(\mathrm{Fc})$, energy consumption and carbon emissions parameters,

$W=\left\{\frac{1}{9}, \frac{1}{9}, \frac{1}{9}, \frac{1}{3}, \frac{1}{3}\right\}$

Following the calculation of weights using AHP, TOPSIS method was applied to rank all available alternatives (the nine given sets) for two different machining processes, separately. TOPSIS provides a solution that is closest to the positive ideal and farthest from the negative ideal. Therefore, by computing the positive and negative ideal solutions, it calculates the relative closeness in terms of the positive ideal solution

Table 5

Pair-wise comparison matrix using AHP.

\begin{tabular}{llllll}
\hline Parameters & $\begin{array}{l}\mathrm{Ra} \\
(\mu \mathrm{m})\end{array}$ & $\begin{array}{l}\mathrm{T} \\
\left({ }^{\circ} \mathrm{C}\right)\end{array}$ & $\begin{array}{l}\mathrm{Fc} \\
(\mathrm{N})\end{array}$ & $\begin{array}{l}\text { Energy } \\
(\mathrm{J})\end{array}$ & $\begin{array}{l}\text { Carbon emissions } \\
(\mathrm{gm})\end{array}$ \\
\hline $\mathrm{Ra}(\mu \mathrm{m})$ & 1 & 1 & 1 & $1 / 3$ & $1 / 3$ \\
$\mathrm{~T}\left({ }^{\circ} \mathrm{C}\right)$ & 1 & 1 & 1 & $1 / 3$ & $1 / 3$ \\
$\mathrm{FC}(\mathrm{N})$ & 1 & 1 & 1 & $1 / 3$ & $1 / 3$ \\
$\begin{array}{l}\text { Energy consumption } \\
\quad(\mathrm{J})\end{array}$ & 3 & 3 & 3 & 1 & 1 \\
$\quad$ Carbon emissions & 3 & 3 & 3 & 1 & 1 \\
\hline
\end{tabular}

which provides ranking to each alternative considered in the study. The steps of TOPSIS method are as follows:

Step 1(a). The normalized decision-making matrix is calculated by normalizing each column corresponding to the given criteria.

$n \mathrm{ij}=\frac{x_{i j}}{\sqrt{\sum_{i=1}^{m} x_{i j}^{2}}} \forall \mathrm{j} \in[1, \mathrm{n}]$

Step 1(b). Subsequently, the weighted normalized decision-making matrix is computed by multiplying weights obtained from AHP to the normalized decision-making matrix.

$S_{i j}=w_{j} n_{i j}, \forall i \in[1, m], j \in[1, n]$

Step 2(a). Next, the positive ideal and negative ideal solutions are determined using

$S_{j}^{+}=\left(s_{1}^{+}, s_{2}^{+}, \ldots, s_{n}^{+}\right)=\left(\left(\max s_{i j} \mid j \in \mathrm{I}\right),\left(\min s_{i j} \mid j \in \mathrm{J}\right)\right)$

$S_{j}^{-}=\left(s_{1}^{-}, s_{2}^{-}, \ldots, s_{n}^{-}\right)=\left(\left(\min s_{i j} \mid j \in \mathrm{I}\right),\left(\max s_{i j} \mid j \in \mathrm{J}\right)\right)$

Step 2(b). Further, the distance is calculated from the positive ideal and the negative ideal solution.

$e_{i}^{+}=\sqrt{\sum_{j=1}^{n}\left(S_{i j}-S_{j}^{+}\right)^{2}}, \forall \mathrm{i} \in[1, \mathrm{~m}]$

$e_{i}^{-}=\sqrt{\sum_{j=1}^{n}\left(S_{i j}-S_{j}^{-}\right)^{2}}, \forall i \in[1, m]$

Step 3. Using these distances, the relative closeness to the positive ideal solution is determined:

$P_{i}=\frac{e_{i}^{-}}{e_{i}^{-}+e_{i}^{+}}, \forall i \in[1, m]$

$P_{\mathrm{i}}$ varies from 0 to 1 . A higher value is desired because it is farther from the negative ideal and closer to the positive ideal solution. It is also evaluated to assess the overall sustainability index i.e., $P_{i}$ under dry, $\mathrm{LN}_{2}$ and $\mathrm{LN}_{2}+\mathrm{MQL}$ conditions. After implementing all steps, the 


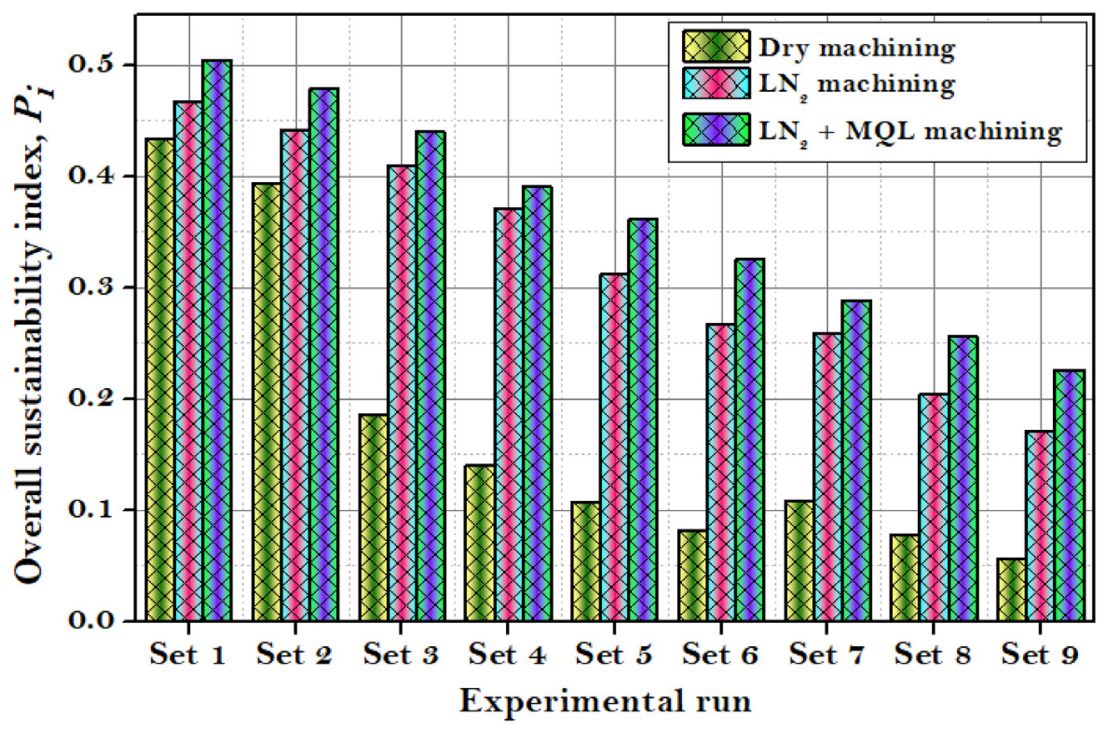

Fig. 14. Overall sustainability index and sustainability assessment results under $\mathrm{dry}, \mathrm{LN}_{2}$ and $\mathrm{LN}_{2}+\mathrm{MQL}$ machining.

sustainability assessment i.e., $P_{i}$ has been calculated and presented in Fig. 14. From this figure, it has been noted that the experimental run \#1 shows the highest sustainability index under all cooling conditions. Instead, the experimental \#9 depicts the lowest value of sustainability index. These results clearly depict that the cutting speed of $100 \mathrm{~m} / \mathrm{min}$ and feed rate of $0.1 \mathrm{~mm} / \mathrm{rev}$ produces the results that are more reliable to the environment and produces low energy and carbon emissions value. These results are calculated based on the TOPSIS-AHP method and the importance of weights assigned to each matrix. When the comparison between cooling conditions have been made, the $\mathrm{LN}_{2}+\mathrm{MQL}$ conditions provides the best results as compared with dry and $\mathrm{LN}_{2}$ machining. The results of $\mathrm{LN}_{2}+\mathrm{MQL}$ cooling conditions are very interesting because it improves the machining performance by considering the environmental aspects. Therefore, it is worthy to mention that the $\mathrm{LN}_{2}+\mathrm{MQL}$ cooling conditions is considered as an environmental friendly cooling conditions.

\section{Conclusions}

The present work deals with the potential of dry, $\mathrm{LN}_{2}$ and $\mathrm{LN}_{2}+\mathrm{MQL}$ machining in turning of commercially available Ti-6Al-4 V. The various environmental, ecological and technological prospective have been deal with in this article. From the given findings, the following conclusions have been summarized:

- The total cycle time and productivity analysis prove that the hybrid $\mathrm{LN}_{2}+\mathrm{MQL}$ cooling conditions produce the best results as compared with dry and $\mathrm{LN}_{2}$ cooling. The improvement of $\mathrm{LN}_{2}$ and $\mathrm{LN}_{2}+\mathrm{MQL}$ was appeared to be $29.01 \%$ and $34.21 \%$ as compared with dry turning.

- Machining cost analysis also confirmed a similar trend and $\mathrm{LN}_{2}+\mathrm{MQL}$ cooling conditions reduce the total process cost up to $65.84 \%$, respectively. In dry turning, the major cost includes the tool cost and energy cost during turning operation. However, these costs are reduced in the case of $\mathrm{LN}_{2}$ and $\mathrm{LN}_{2}+\mathrm{MQL}$ cooling because the tool wear is negligible and the best results have been achieved.

- Energy consumption analysis shows that the $\mathrm{LN}_{2}$ plus MQL consumed around $15.89 \%$ and $3.07 \%$ less energy than dry and $\mathrm{LN}_{2}$ machining, respectively. The main reason is that the lubricating film and cooling effect is provided at the tool chip interface zone, and thereby the low quantum of forces are required to plough the material from a resistant body. Hence, low energy is consumed under $\mathrm{LN}_{2}$ plus MQL cooling conditions. The carbon emission analysis also depicts the same results and a lower value of carbon emission was observed under $\mathrm{LN}_{2}$ plus MQL cooling conditions.

- In terms of machining analysis, low cutting forces, surface roughness and cutting temperature values were observed under $\mathrm{LN}_{2}$ plus MQL cooling conditions. The huge amount of difference has been observed under these values because $\mathrm{LN}_{2}$ plus MQL cooling provides the dual action i.e., cooling and lubrication at the cutting zone. Hence, thin film is generated on the machined surface that protects the machine from vibrations and tool wear and as a result, sound machining characteristics have been observed. On the other hand, $\mathrm{LN}_{2}$ only provides the cooling action and the results are only better as compared with dry machining.

- The combination of AHP and TOPSIS method also provides fruitful results and lower value of cutting speed and feed rate are the ideal parameters that minimally affect the environment as compared with other conditions. Similarly, the $\mathrm{LN}_{2}$ plus MQL cooling condition is claimed as the most sustainable alternative as compared with other cooling conditions.

In this work, the in-depth analysis in terms of machining as well as environmental aspects have been studied. However, some more features such as human health, pollution, vibrations etc. have been missing in the literature. Therefore, these indicators can be explored in future work.

\section{Declaration of Competing Interest}

The authors declare that they have no known competing financial interests or personal relationships that could have appeared to influence the work reported in this paper.

\section{Acknowledgement}

The authors are grateful to the China Post-Doctoral Science Foundation Funded Project (2019TQ0186), National Natural Science Foundation of China (no. 51922066), the Natural Science Outstanding Youth Fund of Shandong Province (Grant No. ZR2019JQ19), the National Key Research and Development Program (Grant No. 2019YFB2005401), and the Key Laboratory of High-efficiency and Clean Mechanical Manufacture at Shandong University, Ministry of Education. The authors declare that there is no conflict of interest. 


\section{References}

[1] K.R. Haapala, F. Zhao, J. Camelio, J.W. Sutherland, S.J. Skerlos, D.A. Dornfeld, et al., A review of engineering research in sustainable manufacturing, J. Manuf. Sci. Eng. Trans. ASME (2013) https://doi.org/10.1115/1.4024040.

[2] V.S. Sharma, M. Dogra, N.M. Suri, Cooling techniques for improved productivity in turning, Int. J. Mach. Tools Manuf. 49 (2009) 435-453, https://doi.org/10.1016/j. ijmachtools.2008.12.010.

[3] K. Gupta, R.F. Laubscher, Sustainable machining of titanium alloys: a critical review, Proc. Inst. Mech. Eng. Part B J. Eng. Manuf. 231 (2016) 2543-2560, https://doi.org/ $10.1177 / 0954405416634278$.

[4] W.S. Yip, S. To, Sustainable manufacturing of ultra-precision machining of titanium alloys using a magnetic field and its sustainability assessment, Sustain. Mater. Technol. 16 (2018) 38-46, https://doi.org/10.1016/j.susmat.2018.04.002.

[5] V.S. Sharma, G. Singh, K. Sørby, A review on minimum quantity lubrication for machining processes machining processes, Mater. Manuf. Process. 6914 (2015) 935-953, https://doi.org/10.1080/10426914.2014.994759.

[6] M. Mia, M.K. Gupta, N.R. Dhar, Evolution of tool flank wear and its influence on machining characteristics in pressurized-oil jet assisted hard turning, J. Prod. Syst. Manuf. Sci. 1 (2020) 2.

[7] M. Mia, M.K. Gupta, C.I. Pruncu, B. Sen, A.M. Khan, M. Jamil, et al., Six sigma optimization of multiple machining characteristics in hard turning under dry, flood, MQL and solid lubrication, J. Prod. Syst. Manuf. Sci. 1 (2020) 6.

[8] G.M. Krolczyk, R.W. Maruda, J.B. Krolczyk, S. Wojciechowski, M. Mia, P. Nieslony, et al., Ecological trends in machining as a key factor in sustainable production - a review, J. Clean. Prod. 218 (2019) 601-615, https://doi.org/10.1016/j.jclepro.2019.02 017.

[9] S. Lei, W. Liu, High-speed machining of titanium alloys using the driven rotary tool, Int. J. Mach. Tools Manuf. (2002) https://doi.org/10.1016/S0890-6955(02)00012-3.

[10] K. Weinert, I. Inasaki, J.W. Sutherland, T. Wakabayashi, Dry machining and minimum quantity lubrication, CIRP Ann. Manuf. Technol. 53 (2004) 511-537, https:// doi.org/10.1016/S0007-8506(07)60027-4.

[11] R.W. Maruda, G.M. Krolczyk, E. Feldshtein, F. Pusavec, M. Szydlowski, S. Legutko et al., A study on droplets sizes, their distribution and heat exchange for minimum quantity cooling lubrication (MQCL), Int. J. Mach. Tools Manuf. 100 (2016) 81-92, https://doi.org/10.1016/j.ijmachtools.2015.10.008.

[12] N.R. Mia, Mozammel Gupta, M.K. Dhar, Evolution of tool flank wear and its influence on machining characteristics in pressurized-oil jet assisted hard turning, J. Prod. Syst. Manuf. Sci. (2020) 1-14.

[13] S. Paul, A.K. Singh, A. Ghosh, Grinding of Ti-6Al-4V under small quantity cooling lubrication environment using alumina and MWCNT nanofluids, Mater. Manuf. Process. (2017) https://doi.org/10.1080/10426914.2016.1257797.

[14] N. Banerjee, A. Sharma, A comprehensive assessment of minimum quantity lubrication machining from quality, production, and sustainability perspectives, Sustain. Mater. Technol. 17 (2018) e00070, https://doi.org/10.1016/j.susmat.2018.e00070.

[15] A. Iqbal, W. Zhao, J. Zaini, N. He, M.M. Nauman, H. Suhaimi, Comparative analyses of multi-pass face-turning of a titanium alloy under various cryogenic cooling and micro-lubrication conditions, Int. J. Light. Mater. Manuf. 2 (2019) 388-396, https://doi.org/10.1016/j.ijlmm.2018.12.004.

[16] J. M, P.K. M, A. R, Effect of LN2 and CO2 coolants in milling of 55NiCrMoV7 steel, J Manuf. Process. (2020) https://doi.org/10.1016/j.jmapro.2020.02.040.

17] A. Shokrani, I. Al-Samarrai, S.T. Newman, Hybrid cryogenic MOL for improving too life in machining of Ti-6Al-4V titanium alloy, J. Manuf. Process. 43 (2019) 229-243, https://doi.org/10.1016/j.jmapro.2019.05.006.

[18] S. Sartori, A. Ghiotti, S. Bruschi, Hybrid lubricating/cooling strategies to reduce the tool wear in finishing turning of difficult-to-cut alloys, Wear 376-377 (2017) 107-114, https://doi.org/10.1016/j.wear.2016.12.047.

[19] J. Schoop, W.F. Sales, I.S. Jawahir, High speed cryogenic finish machining of Ti-6Al4V with polycrystalline diamond tools, J. Mater. Process. Technol. 250 (2017) 1-8, https://doi.org/10.1016/j.jmatprotec.2017.07.002.

[20] B. Dilip Jerold, M. Pradeep Kumar, Experimental comparison of carbon-dioxide and liquid nitrogen cryogenic coolants in turning of AISI 1045 steel, Cryogenics (Guildf.) (2012) https://doi.org/10.1016/j.cryogenics.2012.07.009.

[21] M.K. Gupta, Q. Song, Z. Liu, C.I. Pruncu, M. Mia, G. Singh, et al., Machining characteristics based life cycle assessment in eco-benign turning of pure titanium alloy, J. Clean. Prod. 251 (2020) 119598, https://doi.org/10.1016/j.jclepro.2019.119598.

[22] H.A. Hegab, B. Darras, H.A. Kishawy, Towards sustainability assessment of machining processes, J. Clean. Prod. 170 (2018) 694-703, https://doi.org/10.1016/j. jclepro.2017.09.197.

[23] A.M. Khan, M.K. Gupta, H. Hegab, M. Jamil, M. Mia, N. He, et al., Energy-based cost integrated modelling and sustainability assessment of Al-GnP hybrid nanofluid assisted turning of AISI52100 steel, J. Clean. Prod. 257 (2020) 120502, https://doi. org/10.1016/j.jclepro.2020.120502.
[24] A.T. Abbas, D.Y. Pimenov, I.N. Erdakov, T. Mikolajczyk, M.S. Soliman, M.M. El Rayes, Optimization of cutting conditions using artificial neural networks and the Edgeworth-Pareto method for CNC face-milling operations on high-strength grade-H steel, Int. J. Adv. Manuf. Technol. 105 (2019) 2151-2165, https://doi.org/ 10.1007/s00170-019-04327-4.

[25] A.T. Abbas, D.Y. Pimenov, I.N. Erdakov, M.A. Taha, M.S. Soliman, M.M. El Rayes, ANN surface roughness optimization of AZ61 magnesium alloy finish turning: Minimum machining times at prime machining costs, Materials (Basel) 11 (2018) 808.

[26] A.T. Abbas, D.Y. Pimenov, I.N. Erdakov, M.A. Taha, M.M. El Rayes, M.S. Soliman, Artificial intelligence monitoring of hardening methods and cutting conditions and their effects on surface roughness, performance, and finish turning costs of solid-state recycled Aluminum alloy 6061 chips, Metals (Basel) 8 (2018) 394.

[27] Ç.V. Yildirim, T. Kivak, M. Sarikaya, Ş. Şirin, Evaluation of tool wear, surface roughness/topography and chip morphology when machining of Ni-based alloy 625 under MQL, cryogenic cooling and CryoMQL, J. Mater. Res. Technol. (2019) https://doi.org/10.1016/j.jmrt.2019.12.069.

[28] F. Klocke, G. Eisenblaetter, Dry cutting, CIRP Ann. Manuf. Technol. 46 (1997) 519-526, https://doi.org/10.1016/S0007-8506(07)60877-4.

[29] K.K. Gajrani, D. Ram, M. Ravi Sankar, Biodegradation and hard machining performance comparison of eco-friendly cutting fluid and mineral oil using flood cooling and minimum quantity cutting fluid techniques, J. Clean. Prod. 165 (2017) 1420-1435, https://doi.org/10.1016/j.jclepro.2017.07.217.

[30] G.Y. Zhao, Z.Y. Liu, Y. He, H.J. Cao, Y.B. Guo, Energy consumption in machining: classification, prediction, and reduction strategy, Energy 133 (2017) 142-157, https:// doi.org/10.1016/j.energy.2017.05.110.

[31] Y. Yildiz, M. Nalbant, A review of cryogenic cooling in machining processes, Int. J. Mach. Tools Manuf. 48 (2008) 947-964

[32] S.Y. Hong, Y. Ding, W. Cheol Jeong, Friction and cutting forces in cryogenic machining of Ti-6Al-4V, Int. J. Mach. Tools Manuf. 41 (2001) 2271-2285, https://doi.org/10. 1016/S0890-6955(01)00029-3.

[33] C. Brand, J.M. Preston, '60-20 emission'-The unequal distribution of greenhouse gas emissions from personal, non-business travel in the UK, Transp. Policy 17 (2010) 9-19, https://doi.org/10.1016/j.tranpol.2009.09.001.

[34] Y. Kaynak, T. Lu, I.S. Jawahir, Cryogenic machining-induced surface integrity: a review and comparison with dry, MQL, and flood-cooled machining, Mach. Sci. Technol. 18 (2014) 149-198, https://doi.org/10.1080/10910344.2014.897836.

[35] M.K. Gupta, M. Mia, G.R. Singh, D.Y. Pimenov, M. Sarikaya, V.S. Sharma, Hybrid cooling-lubrication strategies to improve surface topography and tool wear in sustainable turning of Al 7075-T6 alloy, Int. J. Adv. Manuf. Technol. 101 (2019) 55-69, https://doi.org/10.1007/s00170-018-2870-4.

[36] M.K. Gupta, M. Mia, C.I. Pruncu, W. Kapłonek, K. Nadolny, K. Patra, et al., Parametric optimization and process capability analysis for machining of nickel-based superalloy, Int. J. Adv. Manuf. Technol. 102 (2019) 3995-4009, https://doi.org/10.1007/ s00170-019-03453-3.

[37] M.K. Gupta, M. Mia, M. Jamil, R. Singh, A.K. Singla, Q. Song, et al., Machinability investigations of hardened steel with biodegradable oil-based MQL spray system, Int. J. Adv. Manuf. Technol. 108 (2020) 735-748, https://doi.org/10.1007/s00170020-05477-6.

[38] Ç.V. Yıldırım, T. Kıvak, M. Sarıkaya, Ş. Şirin, Evaluation of tool wear, surface roughness/topography and chip morphology when machining of Ni-based alloy 625 under MQL, cryogenic cooling and CryoMQL, J. Mater. Res. Technol. 9 (2) (2020) 2079-2092, https://doi.org/10.1016/j.jmrt.2019.12.069.

[39] A. Bagherzadeh, E. Budak, Investigation of machinability in turning of difficult-to-cut materials using a new cryogenic cooling approach, Tribol. Int. 119 (2018) 510-520, https://doi.org/10.1016/j.triboint.2017.11.033.

[40] M. Sarikaya, A. Güllü, Taguchi design and response surface methodology based analysis of machining parameters in CNC turning under MQL, J. Clean. Prod. 65 (2014) 604-616, https://doi.org/10.1016/j.jclepro.2013.08.040.

[41] L.S. Ahmed, N. Govindaraju, M.P. Kumar, Experimental investigations on cryogenic cooling in the drilling of titanium alloy, Mater. Manuf. Process. 31 (2016) 603-607, https://doi.org/10.1080/10426914.2015.1019127.

[42] T. Kıvak, M. Sarıkaya, Ç.V. Yıldırım, S. Sirin, Study on turning performance of PVD TiN coated Al2O3+TiCN ceramic tool under cutting fluid reinforced by nano-sized solid particles, J. Manuf. Process. 56 (2020) 522-539, https://doi.org/10.1016/j.jmapro. 2020.05.017.

[43] S.A. Lawal, I.A. Choudhury, Y. Nukman, Developments in the formulation and application of vegetable oil-based metalworking fluids in turning process, Int. J. Adv. Manuf. Technol. 67 (2013) 1765-1776, https://doi.org/10.1007/s00170-012-46070.

[44] O.S. Vaidya, S. Kumar, Analytic hierarchy process: an overview of applications, Eur. J. Oper. Res. 169 (2006) 1-29, https://doi.org/10.1016/j.ejor.2004.04.028. 